\title{
TU/e EmonOWEN

\section{Wind tunnel analysis of flow and dispersion in cross-ventilated isolated buildings: impact of opening positions}

\section{Citation for published version (APA):}

Tominaga, Y., \& Blocken, B. J. E. (2016). Wind tunnel analysis of flow and dispersion in cross-ventilated isolated buildings: impact of opening positions. Journal of Wind Engineering and Industrial Aerodynamics, 155, 74-88. https://doi.org/10.1016/j.jweia.2016.05.007

\section{Document license:}

TAVERNE

DOI:

10.1016/j.jweia.2016.05.007

Document status and date:

Published: 26/05/2016

\section{Document Version:}

Publisher's PDF, also known as Version of Record (includes final page, issue and volume numbers)

\section{Please check the document version of this publication:}

- A submitted manuscript is the version of the article upon submission and before peer-review. There can be important differences between the submitted version and the official published version of record. People interested in the research are advised to contact the author for the final version of the publication, or visit the $\mathrm{DOI}$ to the publisher's website.

- The final author version and the galley proof are versions of the publication after peer review.

- The final published version features the final layout of the paper including the volume, issue and page numbers.

Link to publication

\section{General rights}

Copyright and moral rights for the publications made accessible in the public portal are retained by the authors and/or other copyright owners and it is a condition of accessing publications that users recognise and abide by the legal requirements associated with these rights.

- Users may download and print one copy of any publication from the public portal for the purpose of private study or research.

- You may not further distribute the material or use it for any profit-making activity or commercial gain

- You may freely distribute the URL identifying the publication in the public portal.

If the publication is distributed under the terms of Article 25fa of the Dutch Copyright Act, indicated by the "Taverne" license above, please follow below link for the End User Agreement:

www.tue.nl/taverne

Take down policy

If you believe that this document breaches copyright please contact us at:

openaccess@tue.nl

providing details and we will investigate your claim. 


\title{
Wind tunnel analysis of flow and dispersion in cross-ventilated isolated buildings: Impact of opening positions
}

\author{
Yoshihide Tominaga ${ }^{\mathrm{a}, *}$, Bert Blocken ${ }^{\mathrm{b}, \mathrm{c}}$

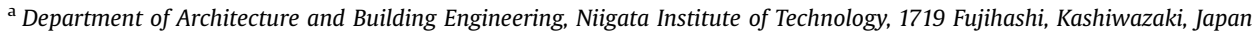 \\ ${ }^{\mathrm{b}}$ Department of the Built Environment, Eindhoven University of Technology, P.O. Box 513, 5600 MB Eindhoven, The Netherlands \\ ${ }^{c}$ Department of Civil Engineering, KU Leuven, Kasteelpark Arenberg 40 - bus 2447, 3001 Leuven, Belgium
}

\section{A R T I C L E I N F O}

Article history:

Received 21 August 2015

Received in revised form

2 May 2016

Accepted 15 May 2016

\section{Keywords:}

Wind tunnel experiment

Cross-ventilation

Pollutant dispersion

Validation

Experimental data set

Window opening position

\begin{abstract}
A B S T R A C T
This paper presents a detailed experimental analysis of flow and dispersion by cross-ventilation in five generic isolated single-zone buildings with different opening positions. First, flow visualization is performed illustrating the highly transient flow and dispersion process dominated by a flapping jet with pronounced Kelvin-Helmholtz instabilities. Next, the mean velocity field, the turbulent kinetic energy field, the mean concentration field and the concentration fluctuation field are presented and analyzed. Finally, time histories of the instantaneous concentration in the building are provided. The contaminant dispersion in the cross-ventilated flow is strongly influenced by the overall flow pattern that is largely determined by the inlet opening position, while the outlet opening position seems less important. The results provide new insights in the flow and dispersion process inside cross-ventilated buildings and can be used to validate Computational Fluid Dynamics (CFD) simulations of flow and dispersion by crossventilation and for the subsequent establishment of new CFD best practice guidelines. It is also shown that the use of different ventilation performance parameters yields a different ranking of the configurations in terms of ventilation performance. Care should therefore be applied when evaluating ventilation performance based on only flow rates or velocities as opposed to dispersion quantities.
\end{abstract}

(c) 2016 Elsevier Ltd. All rights reserved.

\section{Introduction}

Natural ventilation is an important factor in the development of sustainable and healthy indoor environments (e.g. Finnegan et al., 1984; Etheridge and Sandberg, 1996; Carrilho da Graça et al., 2002; Awbi, 2003; Chen, 2009; Tablada et al., 2009; Heiselberg and Perino, 2010; Etheridge, 2011; Karava et al., 2011; van Hooff and Blocken, 2010a, 2014). It is driven by wind or buoyancy, or most often - by a combination of both (e.g. Linden, 1999; Li and Delsante, 2001; Reichrath and Davies, 2002; van Hooff and Blocken, 2010a). In the past decades, a lot of research efforts have contributed to the evaluation of the natural ventilation performance of buildings. Comprehensive reviews on methods for ventilation performance assessment for buildings were provided by Etheridge and Sandberg (1996), Awbi (2003), Chen (2009), Ohba and Lun (2010) and Etheridge (2011). Ventilation performance can be assessed by experiments (e.g. Murakami et al., 1991; Kato et al., 1992; Kato et al., 1997; Linden, 1999; Jiang et al., 2003; Heiselberg et al., 2004; Karava et al., 2007; Tablada et al., 2009; Bu et al., 2010;

\footnotetext{
* Corresponding author. Tel./fax: +81257 228176.

E-mail address: tominaga@abe.niit.ac.jp (Y. Tominaga).
}

Heiselberg and Perino, 2010; Ji et al., 2011; Karava et al., 2011; Karava and Stathopoulos, 2012), analytical and/or semi-empirical formulae (e.g. Linden, 1999; Li and Delsante, 2001; Karava et al., 2004; Etheridge and Sandberg, 1984; Haghighat et al., 1991; Etheridge, 2002; Costola et al.,2009), simulations with zonal and multizone network models (e.g. Li et al., 2000; Hensen, 2004; Hirano et al., 2006; Hensen and Lamberts, 2011) and Computational Fluid Dynamics (CFD) models (e.g. Kato et al., 1992; Kato et al., 1997; Reichrath and Davies, 2002; Jiang et al., 2003; Heiselberg et al., 2004; Evola and Popov, 2006; Norton et al., 2007; Meroney, 2009; van Hooff and Blocken, 2010a, 2010b; Ramponi and Blocken, 2012a; Peren et al., 2015).

Concerning the modeling of dispersion of pollutants, there is a large body of literature concerning dispersion in the outdoor environment (e.g. reviews by Robins, 2003; Meroney, 2004; Ahmad et al., 2005; Li et al., 2006; Tominaga and Stathopoulos, 2013; Di Sabatino et al., 2013; Blocken et al., 2013; Lateb et al., 2016) as well as dispersion in the indoor environment (e.g. Holmberg and Li, 1998; Nazaroff, 2004; Zhao et al., 2004; Zhang and Chen, 2006; Chen et al., 2006; Liu and Zhai, 2007; Gao and Niu, 2007; van Hooff et al., 2013, 2014). Several efforts have focused on dispersion between different indoor environments due to natural ventilation 

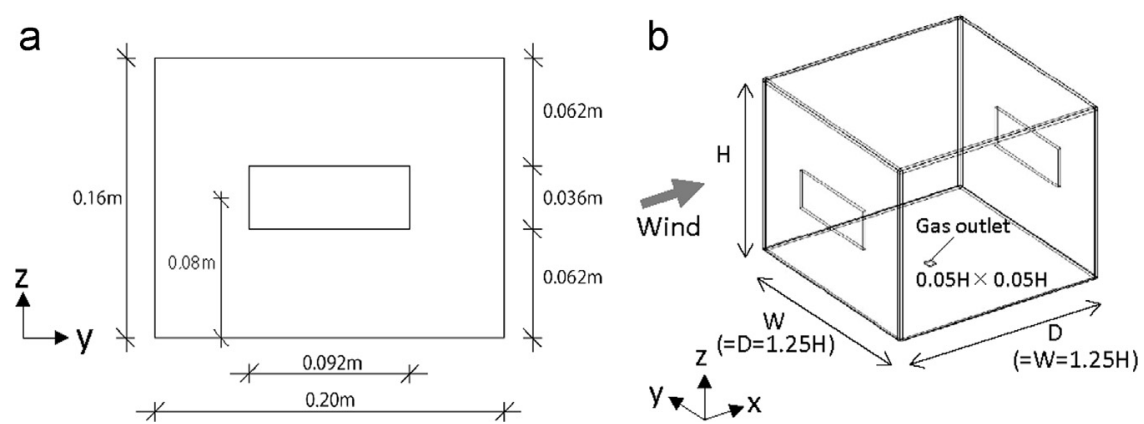

Fig. 1. (a) Front view of model with opening sizes; (b) Schematic view of configuration E.

bringing indoor air via the outdoor environment to another indoor environment. This is called inter-unit dispersion by natural ventilation. Many of these studies emerged from the SARS threat. Examples are the studies by Liu et al. (2007), Niu and Tung (2008), Gao et al. (2008), Ai et al. (2013), Ai and Mak (2014, 2015a, 2015b) and Cui et al. (2016). Two review papers on the topic of inter-unit dispersion by single-sided natural ventilation were provided by $\mathrm{Ai}$ and Mak (2015a, 2015b) and Mao and Gao (2015).

Several studies have analyzed the dispersion of $\mathrm{CO}_{2}$ or other tracers in cross-ventilated buildings using CFD and/or measurements. Many of these studies were performed for greenhouses or livestock buildings in agricultural engineering, e.g. Bartzanas et al. (2004, 2007) and Norton et al. (2009, 2010) who applied 2D or 3D steady and unsteady RANS simulations to assess the air change ratio by natural ventilation. In addition to these studies in agricultural engineering, van Hooff and Blocken (2012, 2013) measured and modeled the dispersion of indoor $\mathrm{CO}_{2}$ by natural crossventilation in a large semi-enclosed stadium in the Netherlands. The CFD simulations were performed with the unsteady RANS equations.

The above-mentioned studies of indoor dispersion by crossventilation are almost exclusively case studies. As opposed to case studies, the literature shows a clear lack of experimental - but also numerical - studies of cross-ventilation with indoor dispersion for generic building configurations. The importance of such experiments is twofold. First, they provide insights in the flow and dispersion process that might be very difficult to obtain from complex case studies in which a large number of parameters are acting simultaneously and jointly influencing the dispersion, e.g. building geometrical details, surrounding buildings and topography, meteorological conditions (temperature, relative humidity, ...) and people, animals or plants. Second, they provide valuable data for dedicated CFD validation studies, which in turn can be used to establish CFD best practice guidelines for this type of flow and dispersion problems.

Given the lack of such studies, this paper presents detailed measurements of flow and dispersion in cross-ventilated buildings in an atmospheric boundary layer wind tunnel. The paper is an extension of a previous paper by the authors on flow and dispersion in a single building configuration (Tominaga and Blocken, 2015). To the best of our knowledge, the present paper is the first to provide detailed experimental data and a detailed analysis of the flow and dispersion process for a set of cross-ventilated generic building configurations. The paper is structured as follows: Section 2 outlines the materials and methods, including the building configurations, the wind tunnel and the wind tunnel setup, and the measurement equipment. Section 3 presents flow visualization performed for the five configurations. Section 4 focuses on the velocity field and Section 5 on the concentration field. Finally, Section 6 summarizes the findings of the study and discusses future prospects.

\section{Materials and methods}

\subsection{Building configurations}

The configurations under study are five generic isolated singlezone buildings with two opposite openings, in the windward and leeward facade. This configuration was made similar to the model used in the extensive experiments by Karava (2008) and Karava et al. (2011) so that the results could be compared. This model was also used in the CFD studies by Meroney (2009) and Ramponi and Blocken (2012a, 2012b). The wind direction is selected to be perpendicular to these facades as in these previous CFD studies. The buildings are 1:100 scale models of a building with full-scale dimensions $\mathrm{W} \times \mathrm{D} \times \mathrm{H}=20 \times 20 \times 16 \mathrm{~m}^{3}$ (Fig. 1). Fig. 1(a) indicates the size and locations of the openings for one of the configurations. The five building configurations only differ from each other by the position of the openings (Fig. 2). Three opening positions are considered: bottom, center, and top. The centers of these openings are at height $h=40,80$, and $114 \mathrm{~mm}$ at reduced scale, respectively. The opening area is $0.036 \mathrm{~m} \times 0.092 \mathrm{~m}=$ $3.3 \times 10^{-3} \mathrm{~m}^{2}$ at reduced scale for all configurations. Due to the horizontally long opening shape, the air movement in the vertical plane is predominant over the lateral motion as shown in the previous paper (Tominaga and Blocken, 2015). This justifies focusing the analysis for the different configurations in the vertical centerplane. A gas outlet with dimensions $8 \mathrm{~mm}(0.05 \mathrm{H}) \times 8 \mathrm{~mm}$ $(0.05 \mathrm{H})$ is located at the center of the floor for each configuration (Fig. 1b).

\subsection{Measurement equipment}

Wind velocity is measured with a split fiber probe (SFP) (Dantec Dynamics; 55R55) and a constant temperature anemometry (CTA) module (Dantec Dynamics; 90C10) for the three components of the velocity vector. The frequency response of this probe in CTA mode is $40 \mathrm{kHz}$. Time-averaging is conducted with a sampling rate of $100 \mathrm{~Hz}$ for a period of $60 \mathrm{~s}$ to obtain statistically stationary values. The uncertainty of the time-averaged velocity is estimated to be within approximately $10 \%$. Ethylene $\left(\mathrm{C}_{2} \mathrm{H}_{4}\right)$, which has a density similar to air, is used as tracer gas. The concentration is measured with a high-speed total hydrocarbon analyzer (Technica, HTHCA-01). The concentration resolution and time response of the hydrocarbon analyzer are $10 \mathrm{ppm}$ and $25 \mathrm{~ms}$, respectively. Uncertainty of the time-averaged data is estimated to be within approximately $15 \%$ in concentration. Fig. 3 displays the measurement positions in the vertical centerplane. Measurements are made at each position by the insertion of the measurement probe and sampling tube through the holes along the centerline in the ceiling of the building model. Unused openings, holes and interspaces are always sealed with tape during the measurements. The diameters of the support for the SFP and the sampling tube of the total hydrocarbon analyzer are $6 \mathrm{~mm}$ and $1 \mathrm{~mm}$, respectively. 

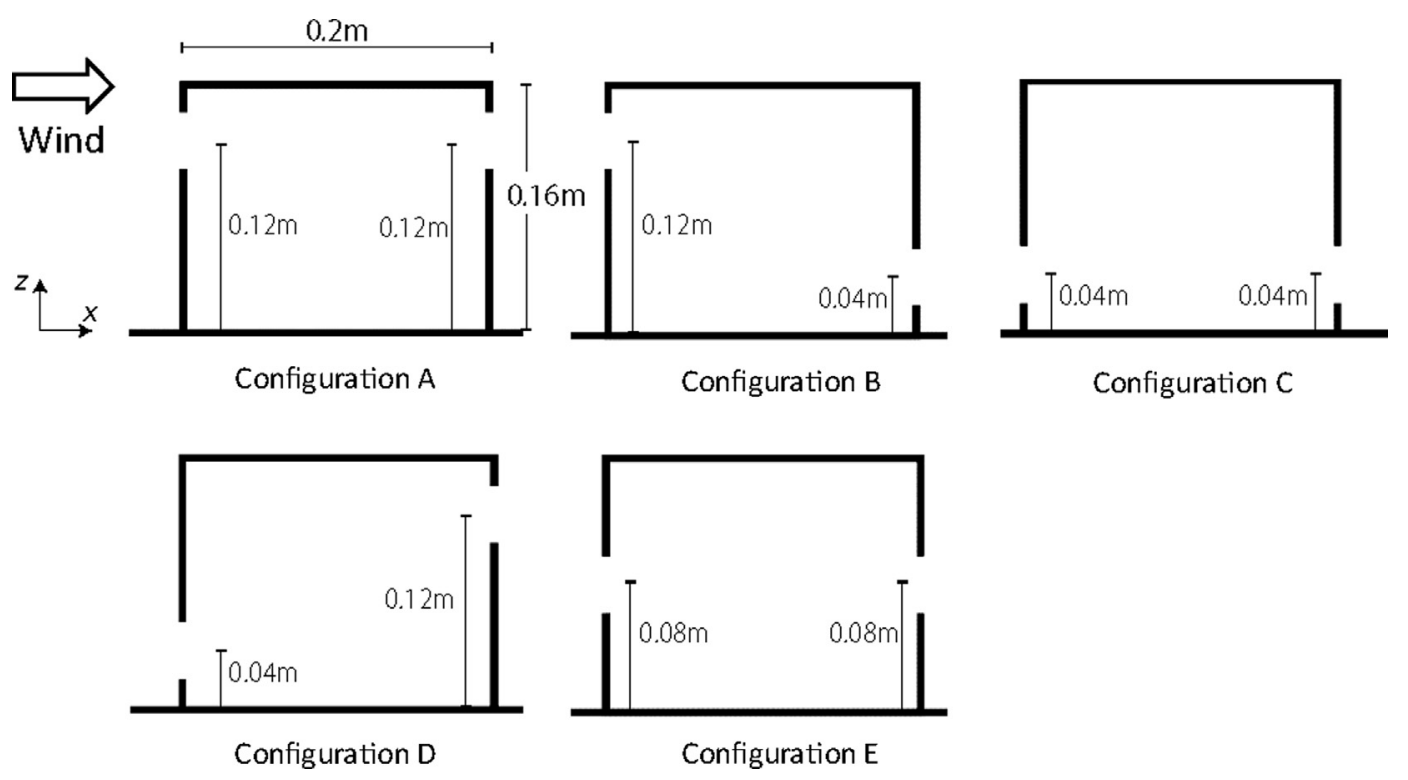

Fig. 2. Vertical sections for each configuration.

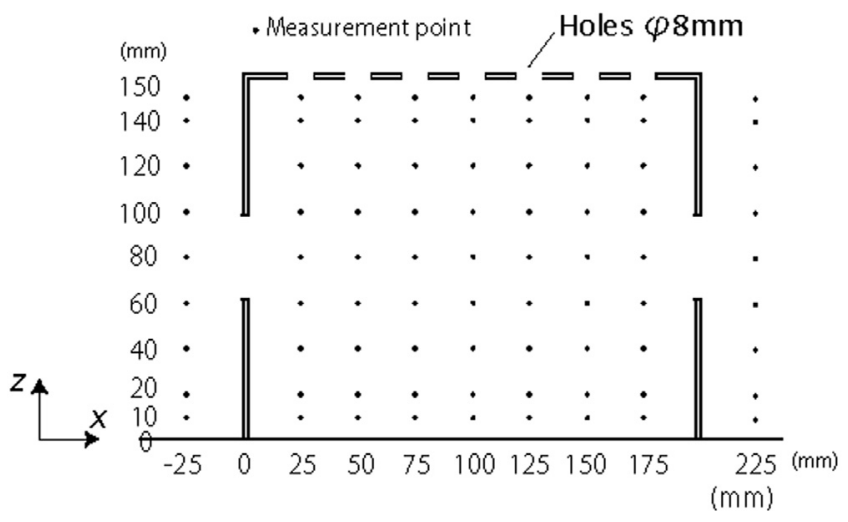

Fig. 3. Measurement points in vertical centerplane.

The air flow rate through the building is measured using the tracer gas method (also using Ethylene). This is performed separately from the detailed measurement for the concentration distributions. Under the condition that the tube releasing the tracer gas is set slightly downstream of the inlet opening, the concentration is measured at slightly upstream of the outlet opening. While the releasing and sampling locations are changing accordingly, the concentrations are measured for each setting and the air change rate is calculated from the spatial-averaged concentration. It is confirmed that the measured concentrations are stationary and, when high concentration due to imperfect mixing of tracer gas and air are detected, the measurement data are excluded from the average. Assuming stationary conditions and perfect mixing of ventilation air and tracer gas, the air flow rate $Q\left[\mathrm{~m}^{3} / \mathrm{s}\right]$ can be estimated by

$Q=\frac{q_{\text {inlet }}}{\overline{C_{\text {outlet }}}}$

with $q_{\text {inlet }}\left[\mathrm{m}^{3} / \mathrm{s}\right]$ the gas emission rate at the inlet openings and $\overline{c_{\text {outlet }}}\left[\mathrm{m}^{3} / \mathrm{m}^{3}\right]$ the time-averaged concentration measured at the outlet openings for $60 \mathrm{~s}$. Repeatability checks are carried out for different release points and the uncertainty of the air flow rate is estimated to be within approximately $\pm 7 \%$.

\subsection{Wind tunnel conditions}

The experiments are carried out in the atmospheric boundary layer wind tunnel at Niigata Institute of Technology (Akabayashi et al., 1996; Yoshie et al., 2007; Kubota et al., 2008; Tominaga and Stathopoulos, 2011) which has a test section of $13 \mathrm{~m}$ length and a cross-section of $1.8 \times 1.8 \mathrm{~m}^{2}$. A combination of spires with height of $1.0 \mathrm{~m}$ and three different upstream surface roughness fetches with roughness heights of $0.10 \mathrm{~m}, 0.05 \mathrm{~m}$ and $0.03 \mathrm{~m}$ are used to create an approach-flow wind profile representative of the lower part of a neutral atmospheric boundary layer. Fig. 4 displays the set-up for the concentration measurements. Fig. 5 shows the incident vertical profiles of the dimensionless mean velocity $\bar{u} / U_{H}$ and turbulent kinetic energy $k / U_{H}{ }^{2}$, i.e. those measured at the center of the empty turntable. The mean streamwise velocity of this incident flow obeys a power law with exponent 0.25 (Fig. 5a):

$\frac{U(z)}{U_{H}}=\left(\frac{z}{H}\right)^{0.25}$

where $U(z)$ and $U_{H}$ are the mean streamwise velocity at height $z$ and at the reference height $H$, respectively. The turbulent kinetic energy $k$ is defined as $k=0.5\left(\sigma_{u}^{2}+\sigma_{v}{ }^{2}+\sigma_{w}{ }^{2}\right)$, where $\sigma_{u}, \sigma_{v}$ and $\sigma_{w}$ denote the standard deviations of the turbulent fluctuations in $x, y$ and $z$ direction, respectively. It is obtained by the three-component measurement of the standard deviations of the velocity fluctuations. This distribution can be approximated by the following expression (Fig. 5b):

$$
\frac{k(z)}{U_{H}^{2}}=0.033 \exp ^{-0.32\left(\frac{z}{H}\right)}
$$

The wind speed at building height $H$ (i.e., $U_{H}$ ) is $4.3 \mathrm{~m} / \mathrm{s}$, yielding a building Reynolds number of about 45,000 , under the condition that the reference velocity at the boundary layer height $(1.0 \mathrm{~m})$ is $7.1 \mathrm{~m} / \mathrm{s}$. A lower velocity of $2.2 \mathrm{~m} / \mathrm{s}$, which was determined by considering the ratio to the exhaust velocity and the optimum concentration range of the calibration curve (100$5000 \mathrm{ppm}$ ), is used as $U_{H}$ to measure the concentration. This value corresponds to a building Reynolds number of about 23,000. An even lower value of $1.7 \mathrm{~m} / \mathrm{s}$ was used for the flow visualization for better visibility, which corresponds to a building Reynolds number of about 18,000 . The vertical profiles of these non-dimensional values are confirmed to be almost identical within the range of the 
experimental velocities.

The emitted Ethylene concentration was $5000 \mathrm{ppm}$ with an emission mass flow rate of $2.0 \mathrm{~L} / \mathrm{min}$ for the concentration measurement. This flow rate corresponds to an exhaust velocity $W_{e}$ of

\section{a}

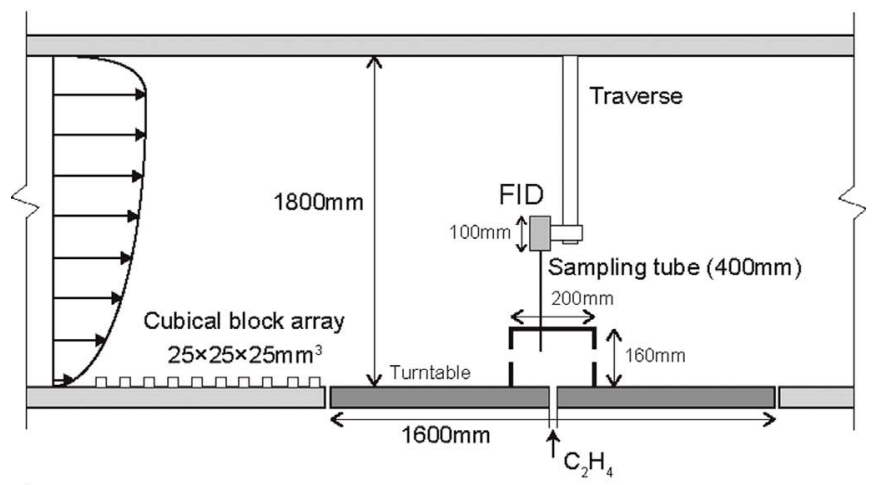

b

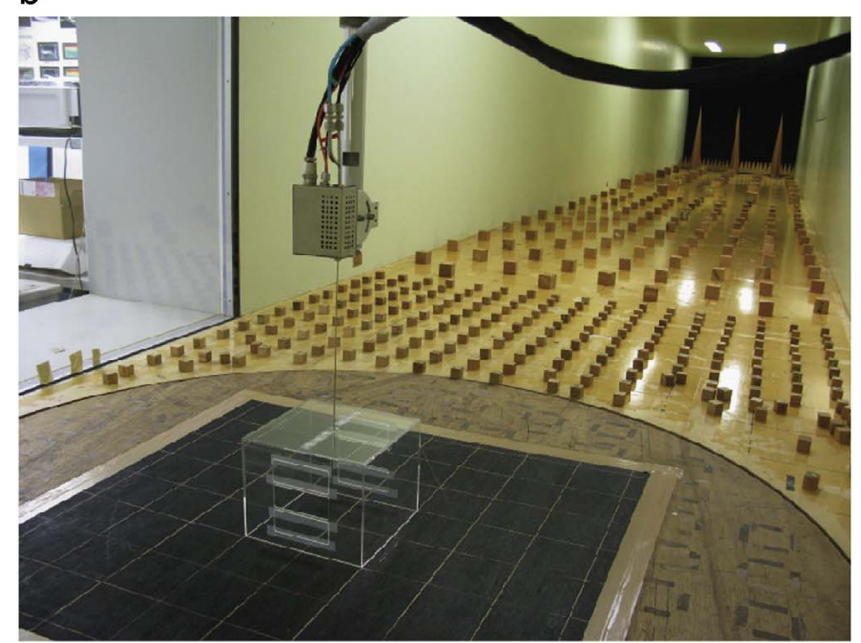

Fig. 4. Experimental set-up in wind tunnel for the concentration measurements: (a) Schematic side view and (b) Photo.
$0.52 \mathrm{~m} / \mathrm{s}$. Therefore, the momentum ratio $W_{e} / U_{H}$ is 0.25 for the series of concentration measurements. The exhaust conditions were determined by the preliminary experiment, in which the approaching wind velocity and the exhaust flow rate were changed, so that the concentration was within the optimum concentration range. Since the ratio of the exhaust flow rate to the air change rate of cross-ventilation was approximately $1-2 \%$, this exhaust velocity was expected to cause only minor disturbance to the flow field inside the building. The concentrations are expressed in non-dimensional form $C^{*}$, where the concentration $c$ is divided by the reference concentration $C_{0}$ given by

$C_{0}=\frac{q_{e}}{H^{2} U_{H}}$

where $q_{e}$ is the pollutant emission rate.

\section{Flow visualization}

Figs. 6-10 each provide 16 images of flow visualizations in the vertical centerplane of each of the five configurations, with a time interval of $1 \mathrm{~s}$ between consecutive images. A laser beam ( $\lambda=532 \mathrm{~nm}, 200 \mathrm{~mW}$, Kato Koken Co.) was used as a light source and converted into a laser sheet parallel to the flow direction by using a cylindrical lens. The thickness of the laser sheet at the visualization plane was about $1 \mathrm{~mm}$. The images were obtained as follows. First, the wind tunnel was started until statistically stationary flow conditions in the building were obtained. Next, while running the tunnel, smoke from a smoke generator was gradually inserted from the ceiling of the model building. Finally, the smoke insertion was removed and camera shots were taken at regular intervals. As a result, Figs. 6-10 show the concentration decay over time. The images are discussed below.

\subsection{Configuration A}

It is well-known in wind engineering that the turbulent wind flow around buildings is highly unsteady with separation, recirculation and von Karman vortex shedding in the wake (Castro and Robins, 1977; Murakami, 1993; Jiang et al., 2003; Tominaga et al., 2008a; Tominaga and Stathopoulos, 2011, 2013; Blocken, 2014). The present study shows that a large degree of unsteadiness
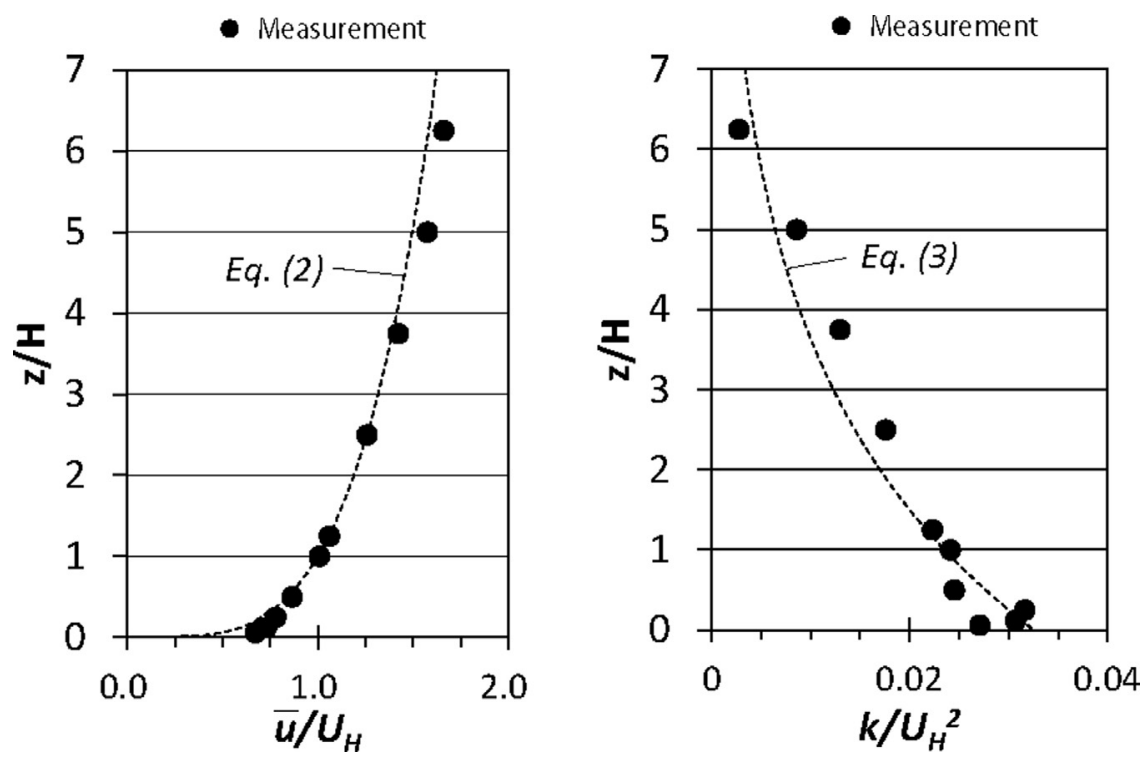

Fig. 5. Inflow profiles of dimensionless mean velocity $\bar{u} / U_{H}$ and turbulent kinetic energy $k / U_{H}{ }^{2}$. 

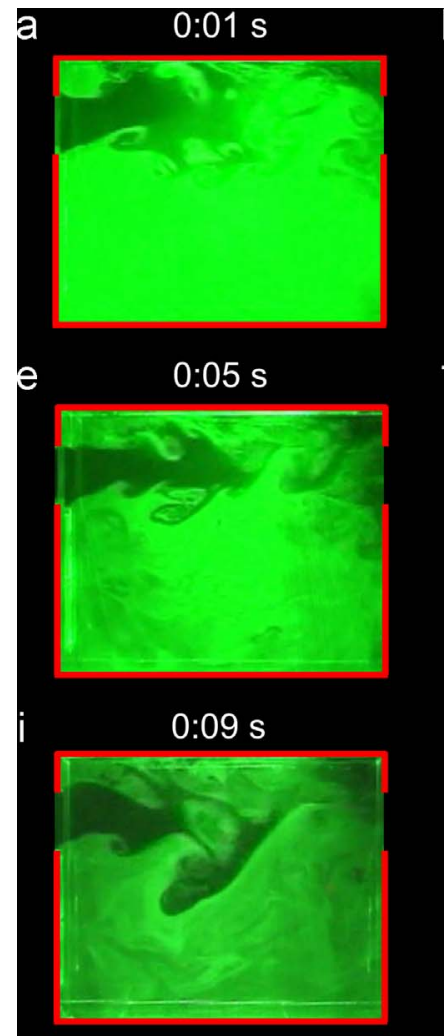

j

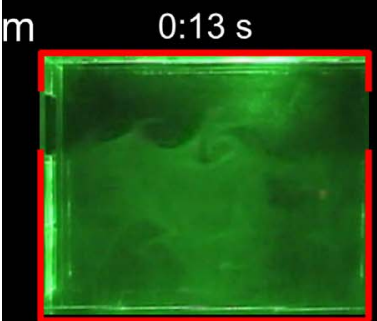

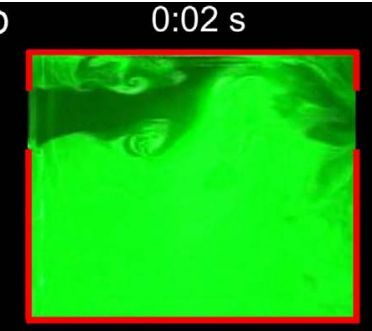

f
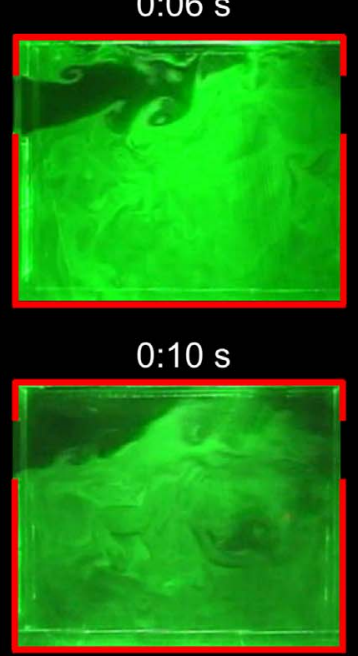

C

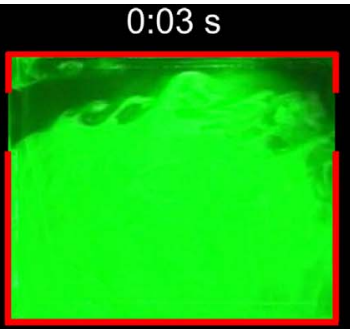

g

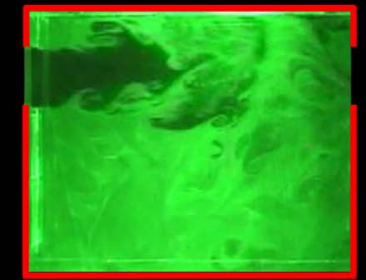

k

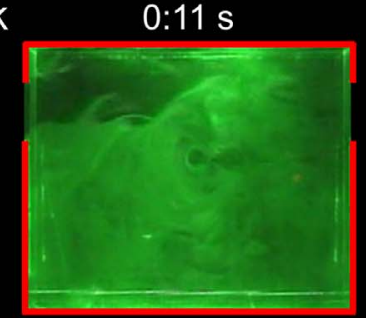

n

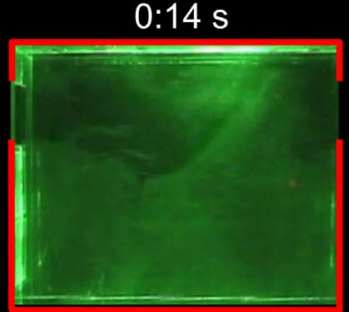

0

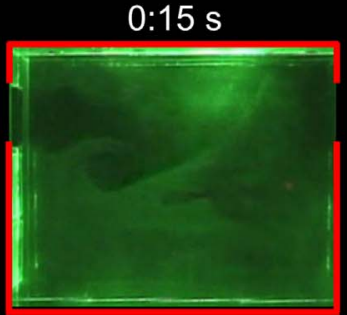

d

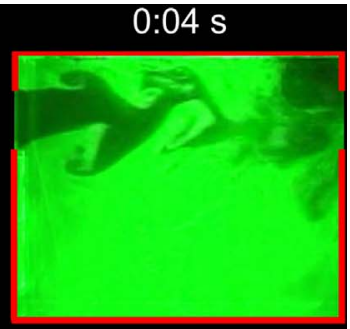

h

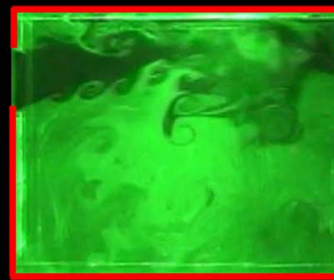

I

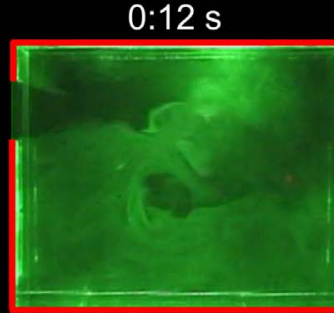

$p$

$0: 16 \mathrm{~s}$

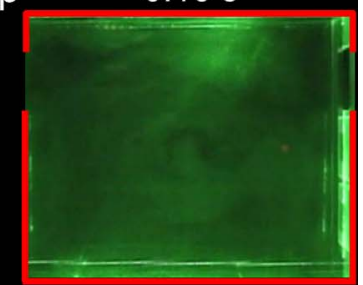

Fig. 6. Flow visualization in vertical centerplane of configuration A. Time interval between consecutive images is $1 \mathrm{~s}$

is also present inside a cross-ventilated building, both concerning the jet of the incoming flow and the overall indoor flow field. Fig. 6 shows that the incoming jet of "fresh" air is mainly directed towards the ceiling due to the so-called Coanda effect. It shows a clear flapping behavior, both upward (see figures c, f, h, j, l, m) and horizontal or even downward (see figures g, i, l, n, o). It also shows a very pronounced Kelvin-Helmholtz instability leading to the formation and shedding of discrete vortical structures. Similar observations were observed in experimental studies of enclosures ventilated by a well-conditioned transitional inlet jet (Nastase et al., 2011, van Hooff et al. 2012a, 2012b). The combination of flapping jet behavior and Kelvin-Helmholz instability is a main reason why the concentration decays in the entire indoor volume, and not only at the top part of the volume. In other words, they limit the short-circuiting behavior that could occur due to a jet passing directly from inlet to outlet opening near the ceiling of the building.

\subsection{Configuration $B$}

Fig. 7 shows very similar flow and concentration patterns as for configuration A. As in Fig. 6, the jet shows a flapping behavior and Kelvin-Helmholtz instability and is mostly directed towards the ceiling by the Coanda effect. Only after having approached the leeward wall, the flow is directed downwards towards the exit opening. As a result, the influence of the position of the outlet opening on the flow and concentration pattern (and ventilation efficiency) is rather limited.

\subsection{Configuration $C$}

As opposed to the jets in configurations $\mathrm{A}$ and $\mathrm{B}$, the jet in configuration C (Fig. 8) is clearly directed downwards, towards the floor of the building. This is attributed both to the Coanda effect and to the structure of the standing vortex upstream of the inlet opening which provides a downward direction to the incoming jet, as demonstrated in (Karava et al., 2011) and (Ramponi and Blocken, 2012a, 2012b). The combination of these two factors substantially reduces the flapping behavior of the jet and the Kelvin-Helmholtz instability as they are suppressed by the presence of the floor. As a result, the interaction between the jet and the flow in the rest of the building is also less pronounced compared to configurations $\mathrm{A}$ and $\mathrm{B}$. As a result, cross-ventilation is less efficient and the concentration levels in configuration $C$ remain much higher than in configurations $A$ and $B$.

\subsection{Configuration $D$}

Fig. 9 shows very similar flow and concentration patterns as for configuration C. As in Fig. 8, the incoming jet shows a downward direction, a less pronounced flapping behavior and less pronounced 


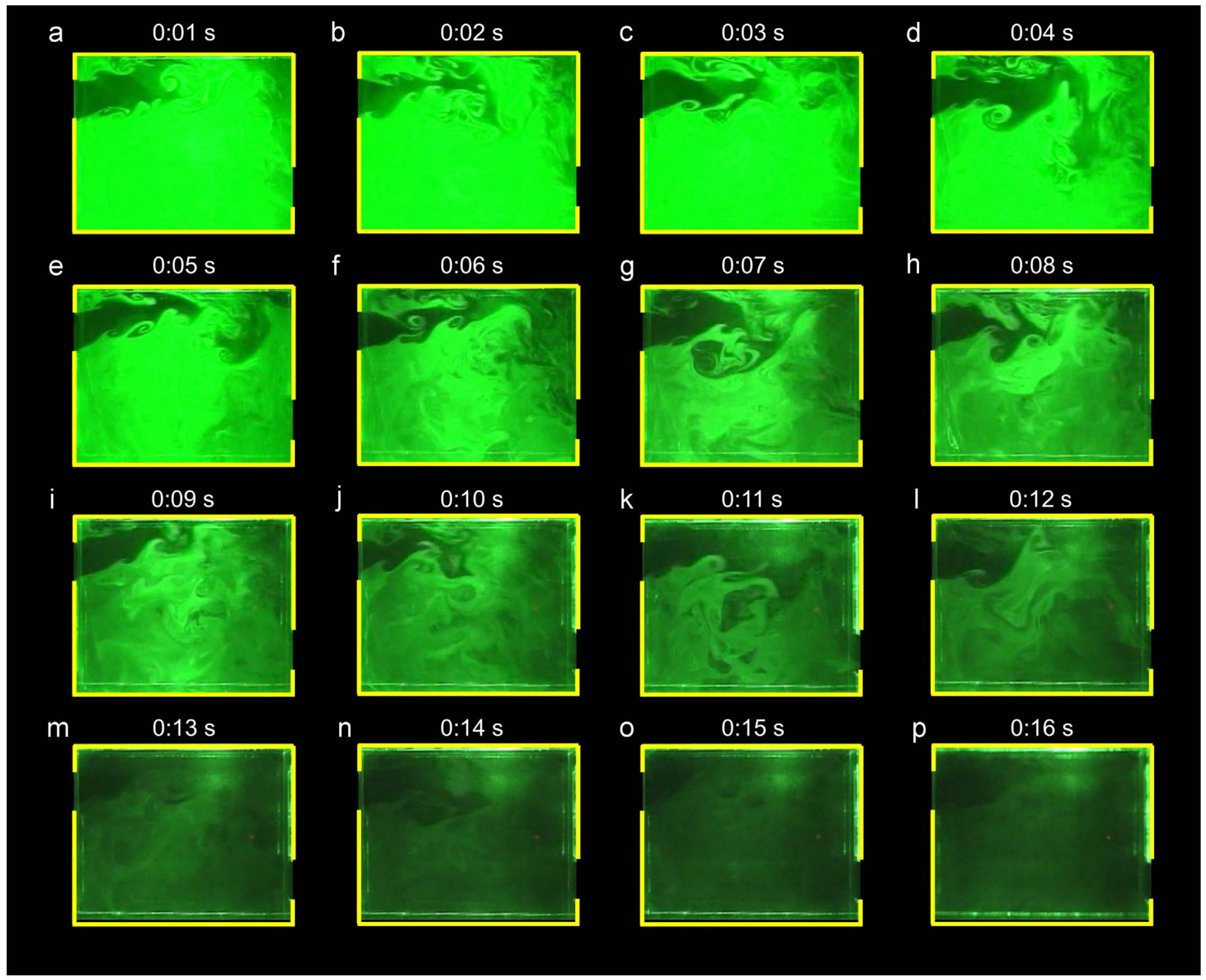

Fig. 7. Flow visualization in vertical centerplane of configuration B. Time interval between consecutive images is $1 \mathrm{~s}$.

Kelvin-Helmholtz instability due to this downward direction and the presence of the floor. Only after having approached the leeward wall, the flow is directed upwards towards the exit opening. As a result, the influence of the position of the outlet opening on the flow and concentration pattern (and ventilation efficiency) is rather limited.

\subsection{Configuration $E$}

Fig. 10 shows a flow and dispersion pattern that is very different from the four preceding configurations. Although the incoming jet flow is on average directed downwards, its flapping behavior is very pronounced as its direction varies between horizontal and inclined downwards with an angle of about $50^{\circ}$. In addition, the jet is characterized by a clear and very pronounced Kelvin-Helmholtz instability leading to the formation and shedding of discrete vortical structures. As these vortical structures are shed from the jet, they subsequently impinge on either the floor, the ceiling or the opposite wall. As a result, the interaction between the jet and the rest of the indoor flow is strong, leading to efficient cross-ventilation and rapid removal of the tracer gas from the indoor volume. Actually, by comparing Figs. 6-10, it can be seen that the pollutant removal efficiency, starting from a uniformly polluted indoor volume, is highest for configuration $\mathrm{E}$.

\subsection{Comparison of results in terms of ventilation efficiency}

Although the visualization for the Figs. 6-10 was only performed in the vertical centerplane, the comparison of color intensity levels in these figures can provide a rough indication about the ventilation efficiency. Assuming that the color intensity in the vertical center section is linearly proportional to the indoor tracer gas concentration, the percentage of concentration decay for the last figure (p) relative to the first figure (a) is $62 \%, 64 \%, 58 \%, 57 \%$ and $78 \%$ for configurations A, B, C, D and E, respectively. These numbers are intentionally not converted to traditional pollutant removal quantities such as ventilation efficiency, residence time or purging flow rate, because of the above-mentioned limitations and assumptions (i.e. only information in vertical centerplane and assumption of linear relationship between color intensity and concentration). Nevertheless, these numbers seem to indicate that indeed the flow pattern and the resulting ventilation behavior of configurations A and B is very similar, and that the same holds for $\mathrm{C}$ and $\mathrm{D}$. E on the other hand seems to be ventilated most efficiently, followed by A-B and finally C-D. This confirms the statements in Sections 3.1-3.5 based on the behavior of the jet in terms of flapping and Kelvin-Helmholtz instability and confirms that these features govern the cross-ventilation and pollutant removal. 


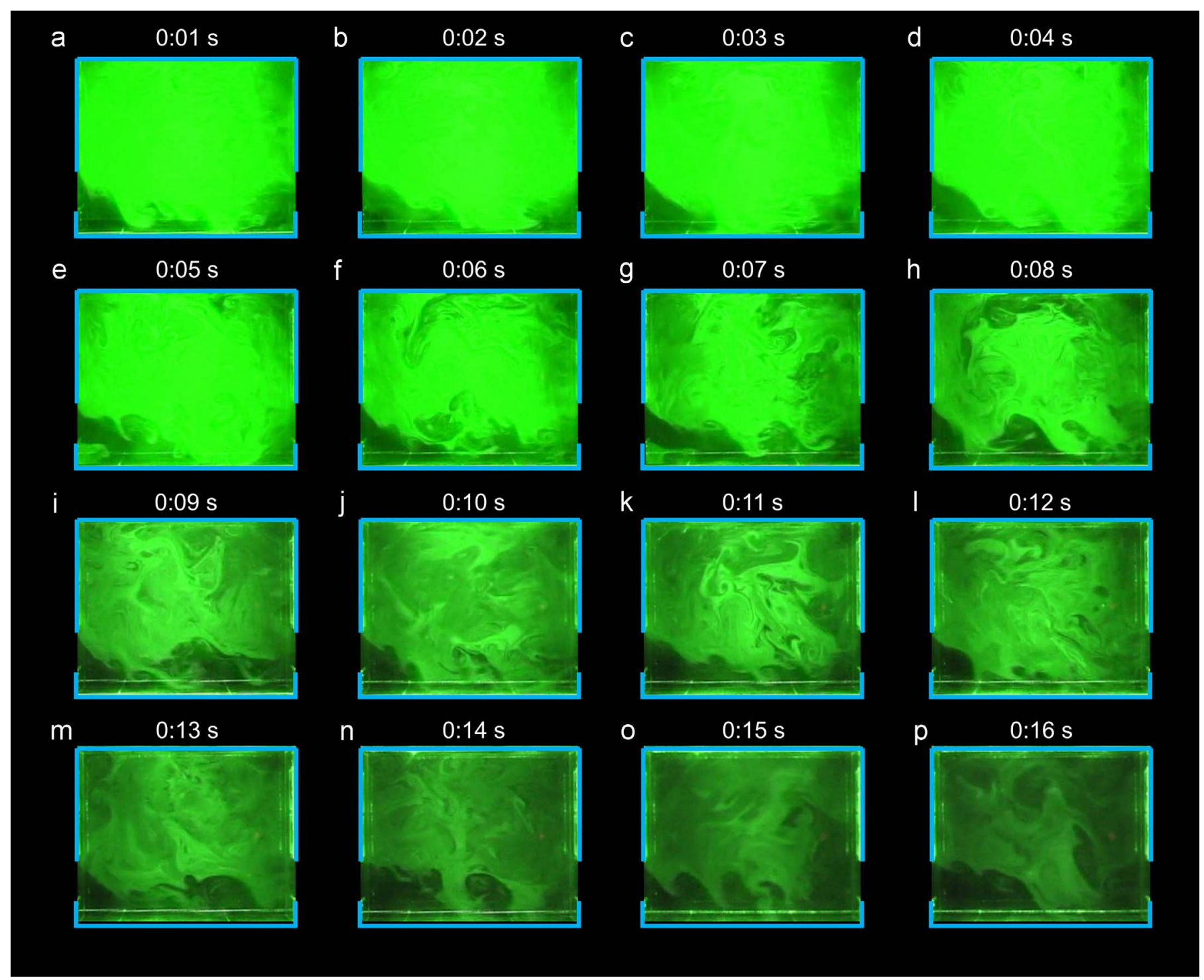

Fig. 8. Flow visualization in vertical centerplane of configuration C. Time interval between consecutive images is $1 \mathrm{~s}$.

\section{Velocity field}

\subsection{Mean streamlines}

Fig. 11 displays the mean velocity field by time-averaged streamlines in the vertical centerplane. The streamlines are constructed as lines that are everywhere parallel to the time-averaged vector field by assuming no lateral component and using the software Tecplot 360.

Fig. 11a shows that the incoming jet is mainly directed upward due to the Coanda effect. Due to entrainment, mainly governed by the flapping jet behavior and the Kelvin-Helmholtz instability (as shown in Fig. 6), the jet drives a large clock-wise recirculation flow in the lower part of the building. The center of this recirculation vortex is situated near the leeward wall.

Fig. 11b displays a jet behavior very similar to Fig. 11a. Only near the leeward wall, the jet is directed downwards towards the outlet opening. Due to the position of the outlet opening near the floor, the vortex center is moved further towards the leeward wall and is actually situated outside the range of the measurement positions.

Fig. 11c shows that the jet that is guided along the floor towards the outlet opening. Although more limited than in configurations $\mathrm{A}$ and $\mathrm{B}$, also here the flapping jet behavior and the Kelvin-
Helmholtz instability drive a large recirculation flow in the upper part of the building. The counter-clockwise circulation is opposite to that in configurations A and B. Also here, the vortex center is too close to the leeward wall to be covered by the discrete set of measurement positions.

Fig. 11d shows that a large recirculation flow is formed with the same direction as Configuration $C$, but with a clearly identified vortex center at a position similar to that of configuration $A$.

Finally, Fig. 11e illustrates the mean downward direction of the jet and the induction of two large recirculating flows, one above and one below the jet, the centers of which are outside the range of the measurement positions. As mentioned before, this downward inflow is attributed to the standing vortex in front of the building (Karava et al., 2011, Ramponi and Blocken 2012a, 2012b).

\subsection{Profiles of mean streamwise velocity}

Fig. 12a shows the rapid decay of the streamwise velocity in the jet due to the entrainment process, as momentum in the jet is transferred to the recirculation cell below the jet. Therefore, the velocity gradients $\partial \bar{u} / \partial z$ are large in the immediate vicinity of the inlet openings and rather small in other areas inside the room. Fig. 12a clearly indicates the clock-wise recirculation cell, with 


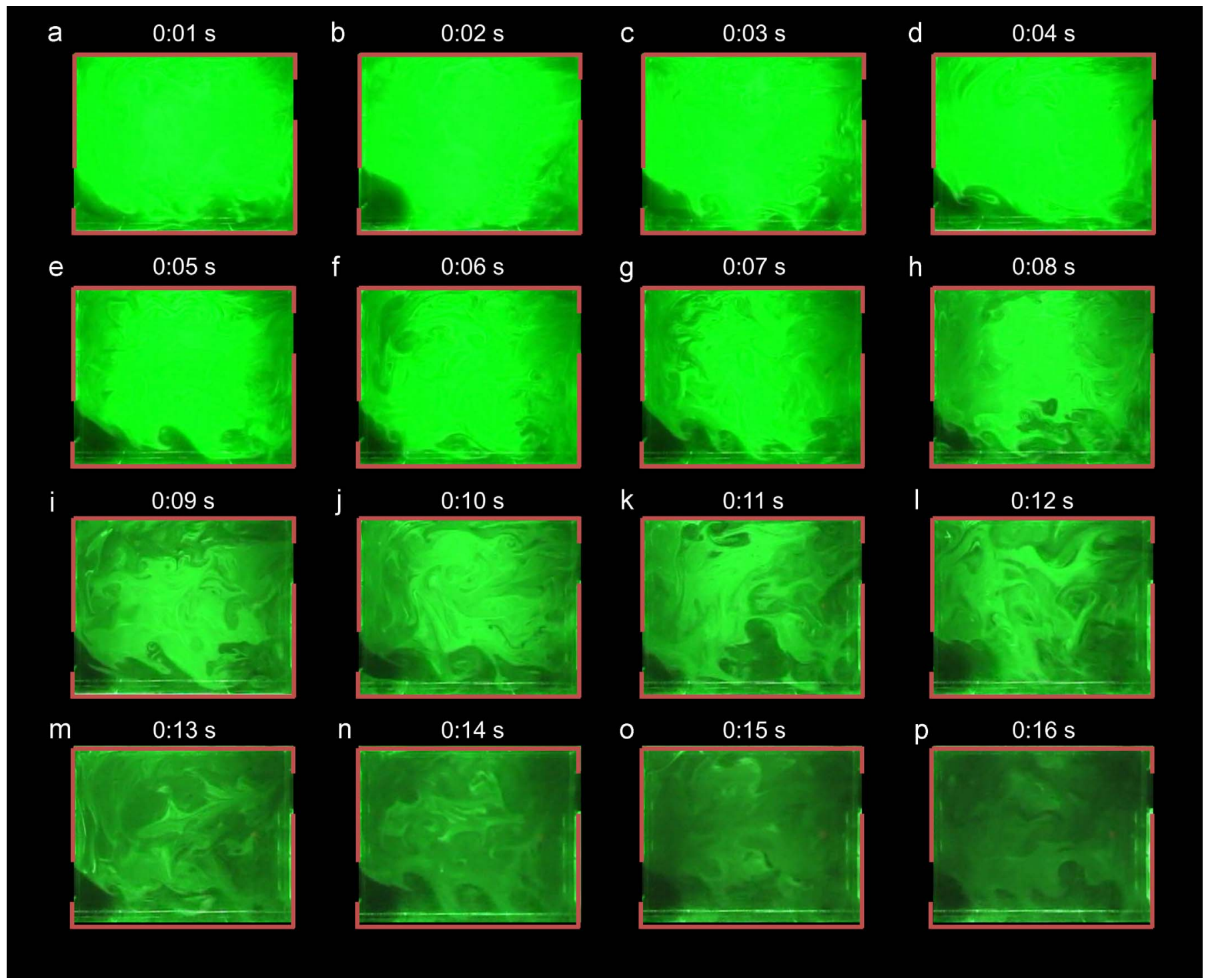

Fig. 9. Flow visualization in vertical centerplane of configuration D. Time interval between consecutive images is $1 \mathrm{~s}$.

positive streamwise velocity in the upper part and negative streamwise velocity in the lower part of the building. The streamwise velocity component $\bar{u} / U_{H}$ is about -0.26 and directed to the windward facade at the nearest measurement point to the source.

The streamwise velocity in the jet in Fig. 12b is lower than in Fig. 12a, which is attributed to the different position of the outlet opening, which causes a larger overall indoor flow resistance. Also the velocities in the recirculation cell are lower than in configuration $\mathrm{A}$, for the same reason. $\bar{u} / U_{H}$ is about -0.20 and directed to the windward facade at the nearest measurement point to the source.

Fig. 12c shows a streamwise velocity in the jet that is even lower than in configurations A and B. This is attributed to the lower velocity (and lower static pressure) outside the building near the lower inlet opening (cfr. Ramponi and Blocken, 2012a). $\bar{u} / U_{H}$ is about 0.62 and directed to the leeward façade at the nearest measurement point to the source. It is larger due to both the concentrated near-wall jet and the vicinity of the inlet opening which reduces the overall flow resistance.

The streamwise velocities in Fig. 12d are only slightly lower than in configuration $C$. This is attributed due to the top position of the outlet opening, which increases the overall resistance of the indoor jet flow compared to configuration C. For the same reason, also the streamwise velocities in the recirculation cell are lower. $\bar{u} / U_{H}$ is about 0.56 and directed to the leeward facade at the nearest measurement point to the source.

Finally, Fig. 12e clearly shows a wide incoming jet. This larger width is associated with the flapping behavior and strong KelvinHelmholtz instability, which are more pronounced than in all preceding configurations. $\bar{u} / U_{H}$ is very small (0.09) and slightly directed to the leeward facade at the nearest measurement point to the source.

\subsection{Profiles of turbulent kinetic energy}

Fig. 13 shows profiles of the turbulent kinetic energy normalized by the square of the mean reference wind speed $U_{H}$. In general, the turbulent kinetic energy $k$ is large where the velocity gradient $\partial \bar{u} / \partial z$ is large. However, the maximum peak of $k$ also occurs upstream of the leeward openings for configurations $B$ and $\mathrm{D}$, where the velocity gradient $\partial \bar{u} / \partial z$ is not so large. This is because the velocity gradients of the vertical component, i.e., $\partial \bar{w} / \partial x$ and $\partial \bar{w} / \partial z$, are large in this region due to the strong curvature in the locally separating and recirculating flow. Examples are the outlet regions in configurations $\mathrm{B}$ and $\mathrm{D}$. 


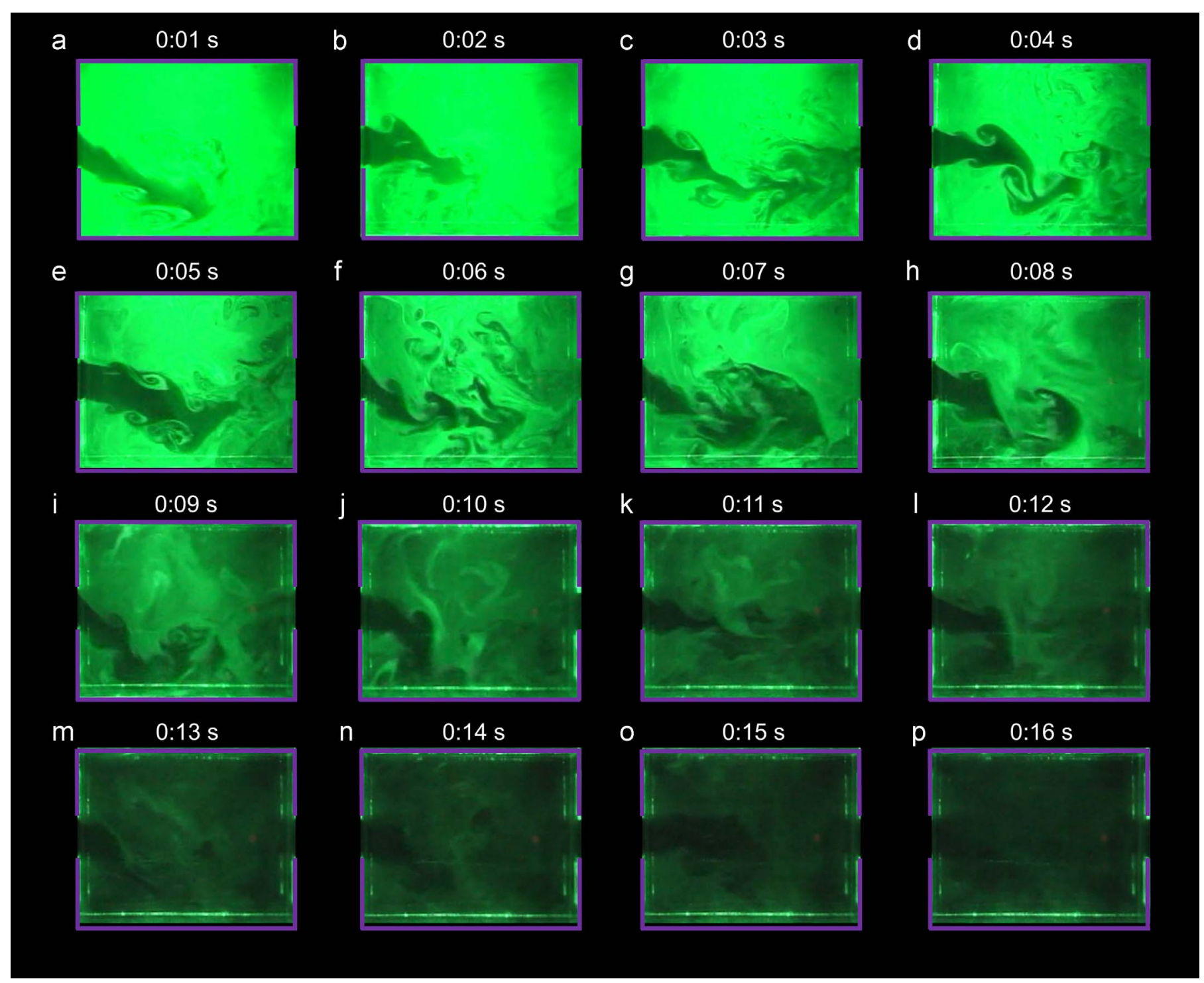

Fig. 10. Flow visualization in vertical centerplane of configuration E. Time interval between consecutive images is $1 \mathrm{~s}$.

\section{Concentration field}

\subsection{Mean concentration}

Given the steady pollutant exhaust in the middle of the floor, Fig. 14 shows the contours of the time-averaged concentration $C^{*}=\bar{c} / C_{0}$ in the vertical centerplane. The indoor pollutant distribution is determined by the combination of source location and the indoor flow pattern. Also here, especially the location of the inlet opening appears important, while the effect of the location of the outlet opening is rather limited.

Fig. 14a shows that the pollutant is convected towards the windward facade, due to the direction and magnitude of the mean flow near the source. A similar mean concentration pattern is observed for configuration $\mathrm{B}$. The fact that the mean streamline pattern for A and B shows some clear differences that are not clearly represented in the concentration field, suggests the importance of turbulent mixing. Fig. 14c shows that in configuration $\mathrm{C}$, the pollutant is very effectively removed due to the jet passing directly over the source and directly towards the outlet. Similar observations are made for configuration D. Fig. 14e finally shows that configuration E exhibits a very different concentration pattern, mainly governed by the more central location of the jet and the two distinct recirculation cells at both sides of the jet.

The space-averaged concentration values in the vertical centerplane are $C^{*}=32,36,17,28$ and 32 for configurations $\mathrm{A}, \mathrm{B}, \mathrm{C}, \mathrm{D}$ and $\mathrm{E}$, respectively. Note that the order of configurations with the highest pollutant removal rate from the visualizations with a uniformly distributed pollutant at the start $(\mathrm{E}-\mathrm{A} / \mathrm{B}-\mathrm{C} / \mathrm{D})$ is very different from the order of configurations with highest pollutant removal rate with a source at the center of the floor $(C, D, A / E, B)$. This indicates that parameters such as the air change rate $(A C H)$ are not necessarily the best measures for ventilation efficiency, and that it is important to consider the position of the source(s).

Fig. 15 shows the related concentration profiles. Large local concentration values are present in configurations $\mathrm{C}, \mathrm{D}$ and $\mathrm{E}$, but they are limited to the lower part of the room. Although the large local concentration values are probably also present closer to the source in configurations A and B, they are not caught at the nearest measurement point to the source due to the respective flow patterns.

\subsection{Concentration fluctuations}

Fig. 16 shows the vertical profiles of the RMS values of the concentration fluctuations in the centerplane. In general, the 

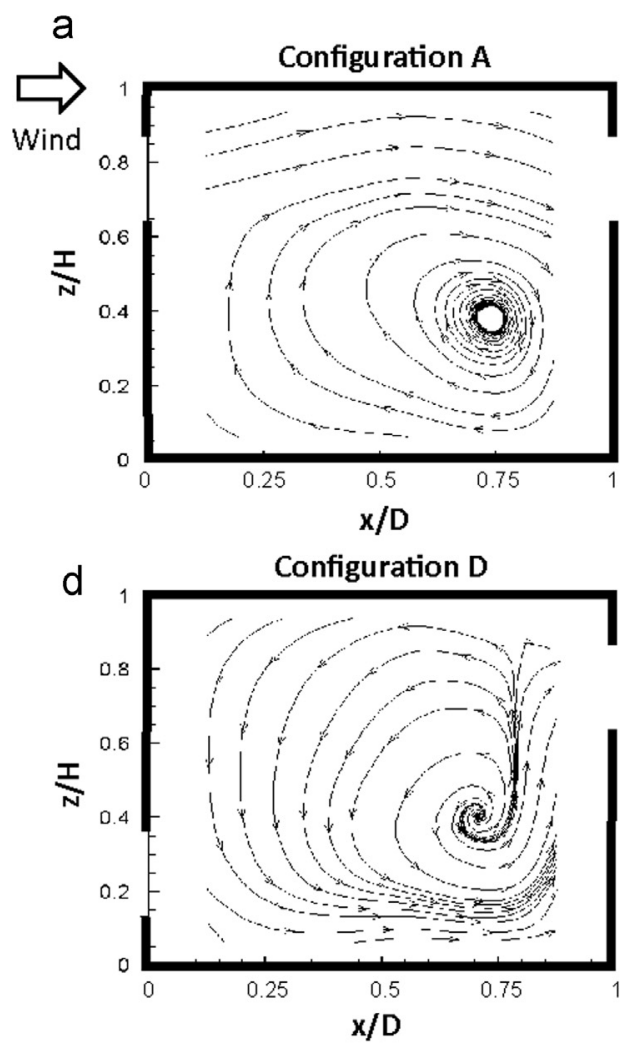

b

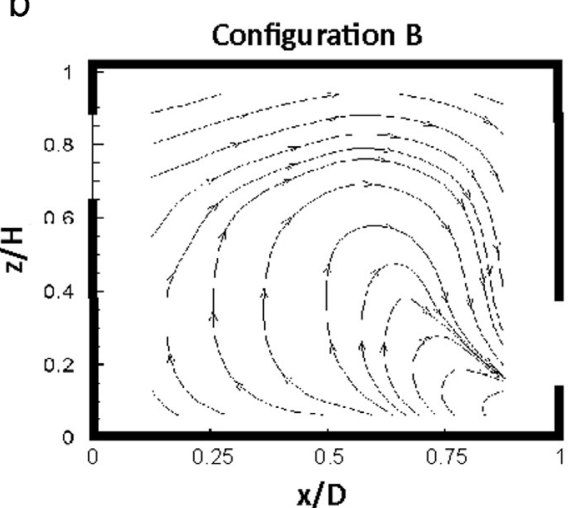

C

Configuration $\mathrm{C}$

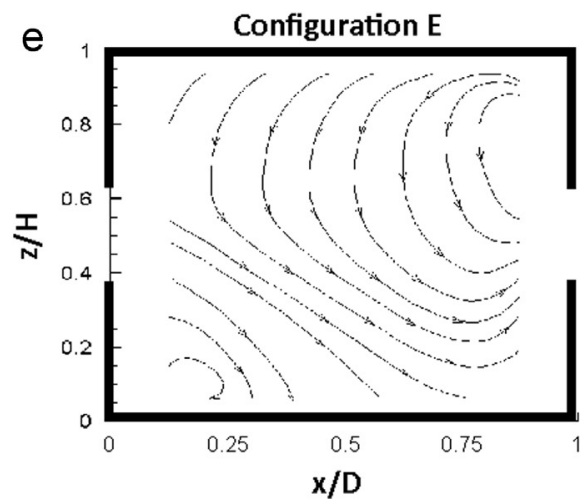

Fig. 11. Time-averaged streamlines in vertical centerplane for configurations A, B, C, D and E.
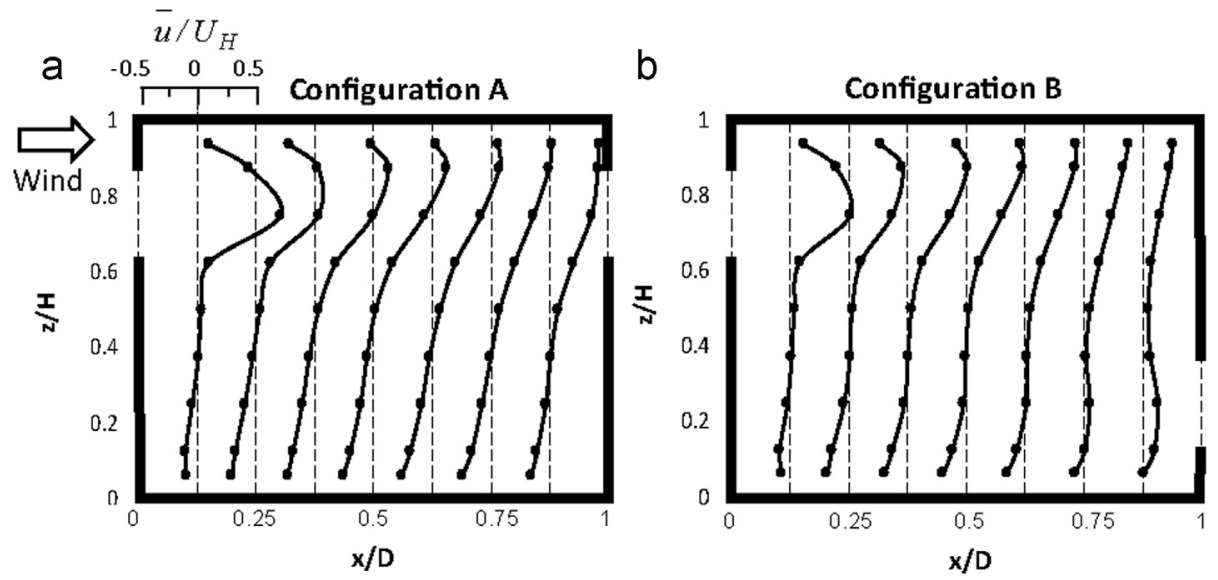

C
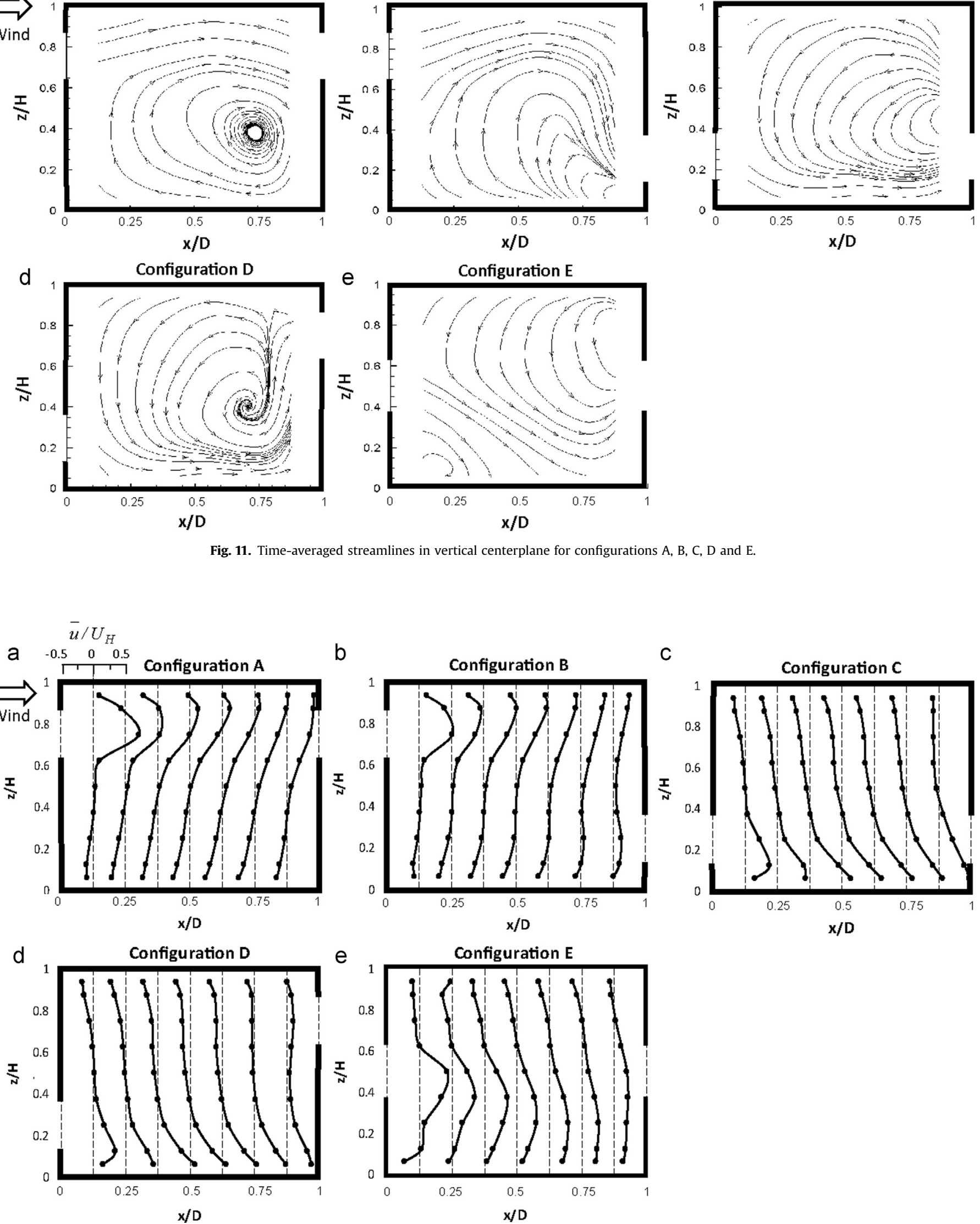

Fig. 12. Vertical profiles of time-averaged streamwise velocities $\bar{u} / U_{H}$ in vertical centerplane for configurations A, B, C, D and E. 


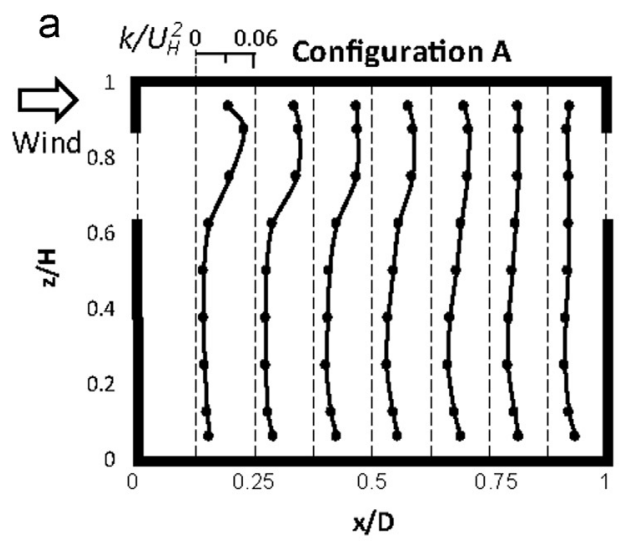

b
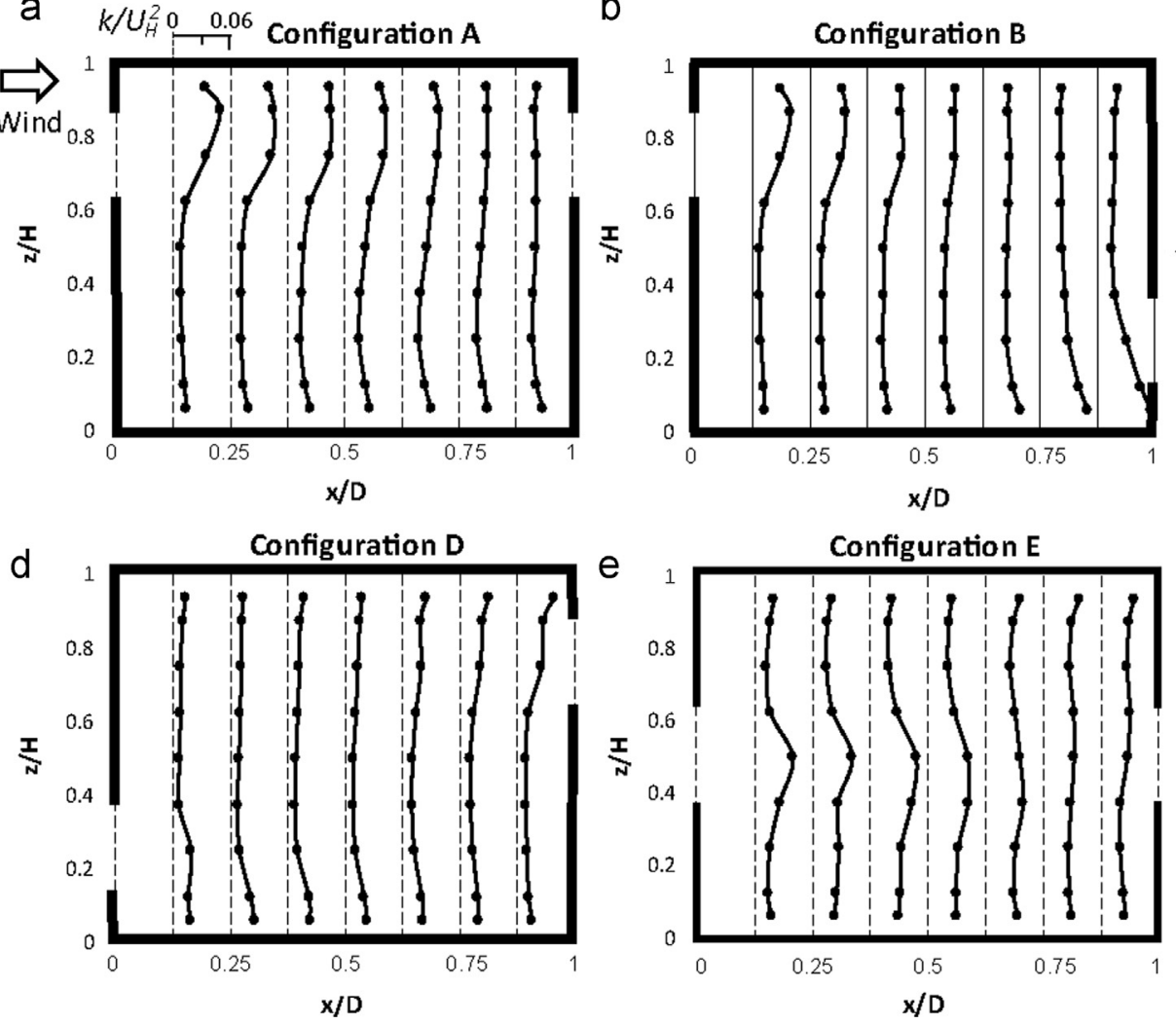

C

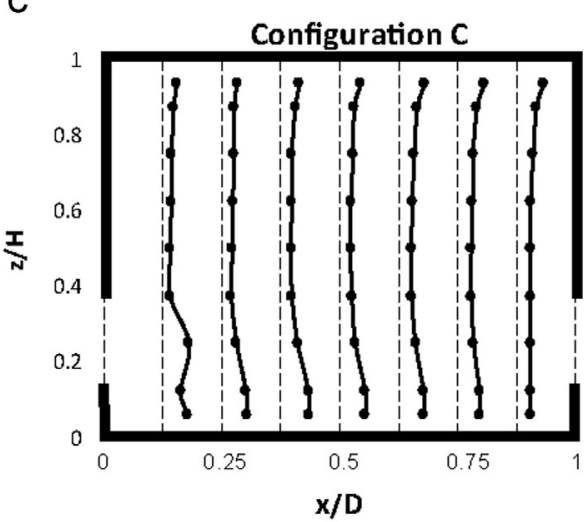

Fig. 13. Vertical profiles of turbulent kinetic energy $k$ at vertical center sections for configurations A, B, C, D and E.

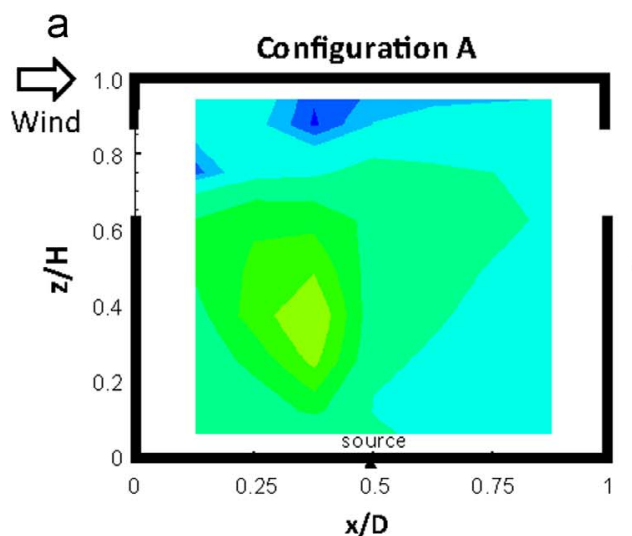

b

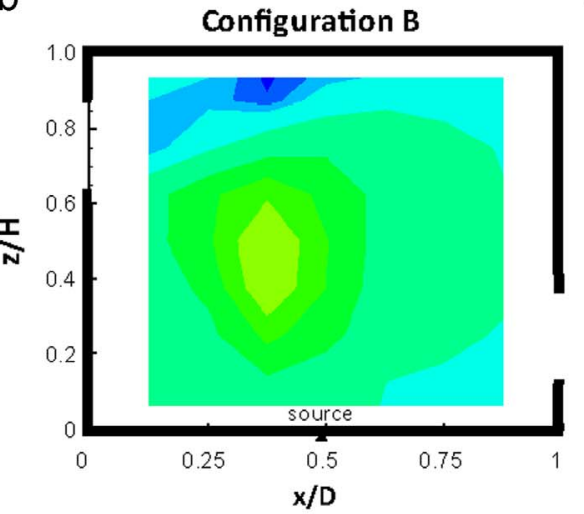

C
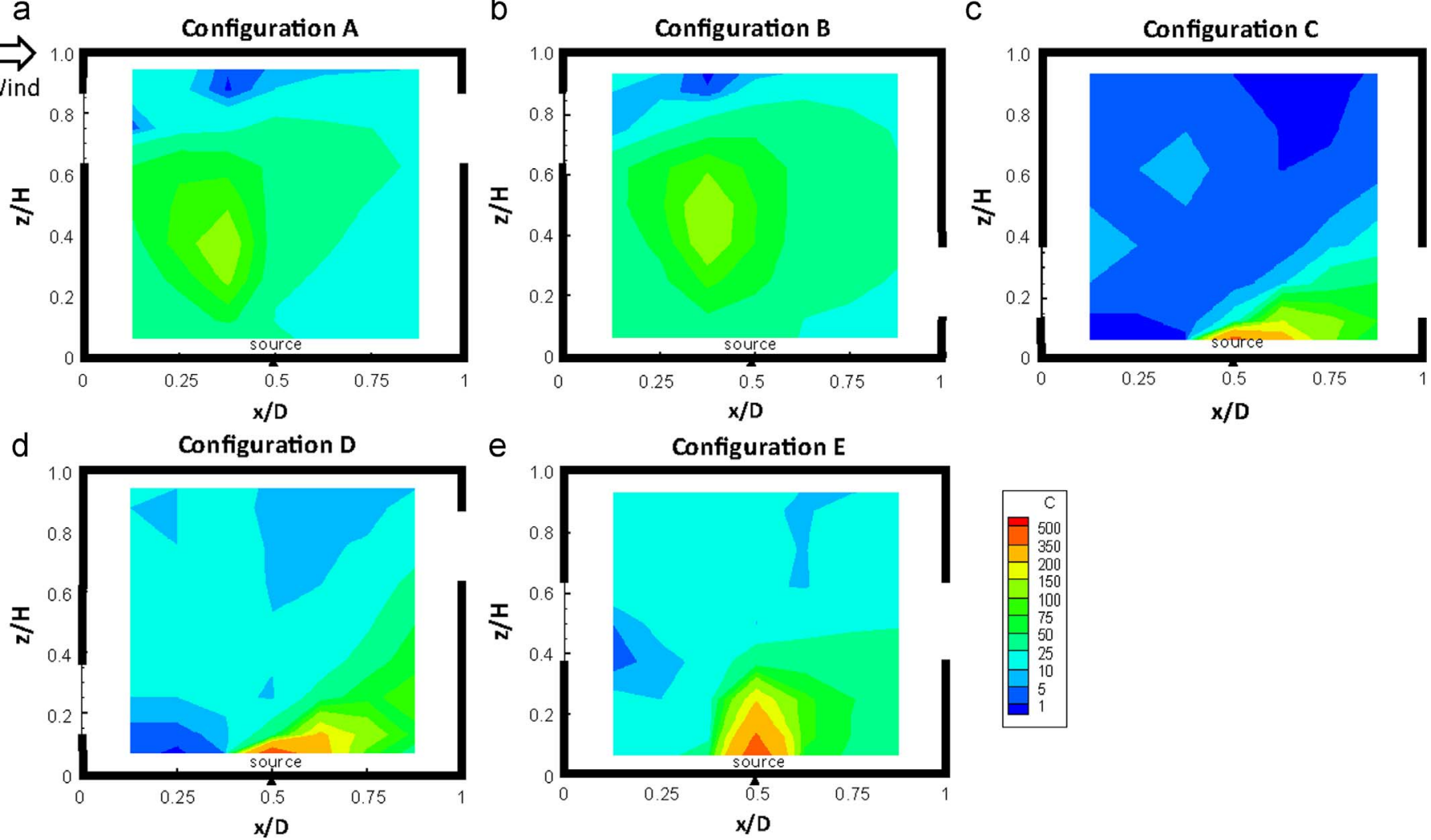

e

Configuration $\mathrm{E}$
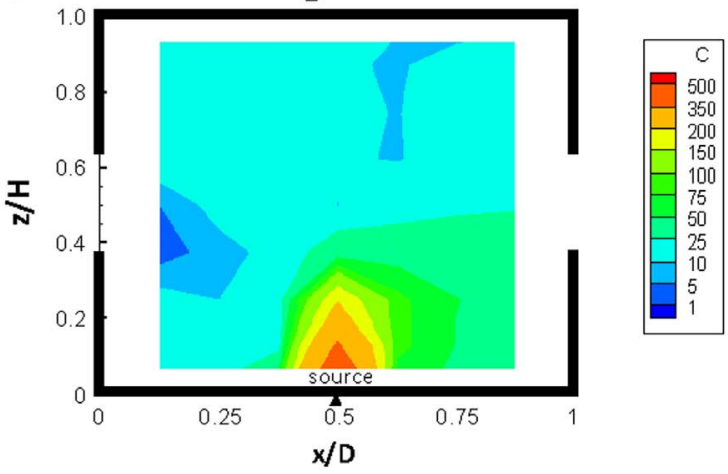

Fig. 14. Contours of time-averaged concentrations $\bar{c} / C_{0}$ in vertical centerplane for configurations $\mathrm{A}, \mathrm{B}, \mathrm{C}, \mathrm{D}$ and $\mathrm{E}$. 

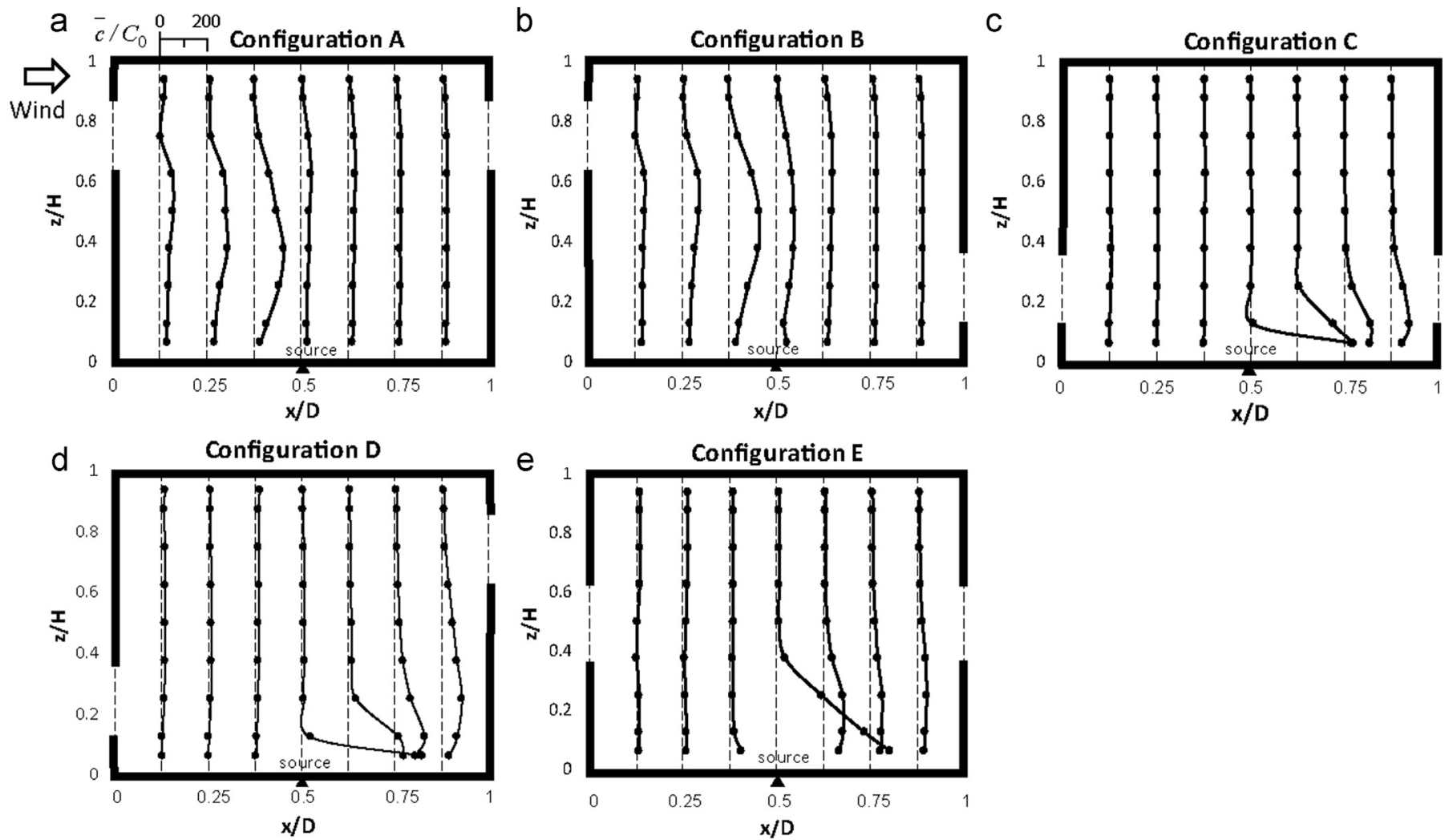

Fig. 15. Vertical profiles of time-averaged concentrations $\bar{c} / C_{0}$ in vertical centerplane for configurations $\mathrm{A}, \mathrm{B}, \mathrm{C}, \mathrm{D}$ and $\mathrm{E}$.

concentration fluctuations tend to be large where the spatial gradient of the mean concentration is large. A similar tendency for the distribution of $\sqrt{\bar{c}^{2}} / C_{0}$ was reported in the experimental results of the concentration measured in a street canyon flow ( $\mathrm{Pa}-$ vageau and Schatzmann, 1999). Because the production term of the transport equation for $\bar{c}^{2}$ is expressed as $-\overline{u_{i}{ }^{\prime} c^{\prime}} \frac{\partial \bar{c}}{\partial x_{i}}$, the large negative mean concentration gradient $\partial \bar{c} / \partial z$ near the source contributes to the large production of $\overline{c^{2}}$. Note that the distributions of $k$ and $\overline{c^{\prime 2}}$ are completely different. The values are very large near the source, particularly in configurations C, D and E. It is confirmed that the distribution of concentration fluctuations are mainly influenced by the mean concentration field determined by the main flow patterns, while the velocity fluctuations are mostly produced by the velocity shear around the incoming jet.

\section{Air change rate}

Table 1 compares the measured air flow rates $Q$ normalized by $U_{H}$ and the area of the inlet opening $A_{\text {inlet }}$ for the five building configurations. Although the openings are rather large and the internal resistance of the building zone is very low, the air flow rates for different configurations differ by up to $40 \%$. Configuration $A$ has the highest air flow rate, and configurations $C$ and $D$ had the lowest air flow rates. This demonstrates that the air flow rate is strongly influenced by the height of the inlet opening, in line with the findings by Karava et al. (2011). However, even when the location of the inflow opening was the same, a substantial difference was observed, as seen for configurations A and B. This was mainly caused by the momentum loss of the incoming flow impinging on the opposite wall, which did not occur in configuration A, but which is large in configuration B.

\section{Comparison of ventilation performance parameters}

In this paper, different parameters that could be used to evaluate the ventilation performance of the building were considered.

The flow visualization exercise considered the removal of a uniformly distributed indoor pollutant. Assuming that the color intensity in the vertical center section is linearly proportional to the indoor tracer gas concentration, the percentage of concentration decay for the last figure $(\mathrm{p})$ relative to the first figure leads to the ranking (from best to worst ventilated): E (78\%), B (64\%), A (62\%), C (58\%) and D (57\%). This ranking is mainly governed by the efficiency of the entrainment process by the flapping jet and the Kelvin-Helmholtz-instability, which is largest in configuration $\mathrm{E}$, lower in configurations A and $\mathrm{B}$ (where they are restriction by the ceiling) and lowest in configurations $\mathrm{D}$ and $\mathrm{E}$ (where they are restricted by the floor).

The space averaged concentrations for the case with pollutant source at the center of the floor lead to the ranking (from best to worst ventilated): C (17), D (28), A and E (32) and B (36). Evidently, this ranking is mainly determined by the combination of both the position of the pollutant source and the indoor flow pattern.

The time averaged concentrations in the sampling point in Fig. 17 lead to the ranking (from best to worst ventilated): C (4), D (11), A (35), E (38), B (74). This ranking is mainly determined by the combination of the position of the pollutant source, the indoor flow pattern and the position of the sampling point.

Finally, the assessment of the air change rate leads to the ranking (from best to worst ventilated): A (0.37), B (0.27), E (0.25), $\mathrm{C}(0.23), \mathrm{D}(0.22)$. This ranking is determined by the position of the inlet opening (which to a large extent determines the pressure driving the cross-ventilation flow) and the indoor airflow resistance, which is larger when inlet and outlet opening are at different heights than at the same height.

It is important to note that each ventilation performance parameter considered leads to a different ranking, as each parameter is 


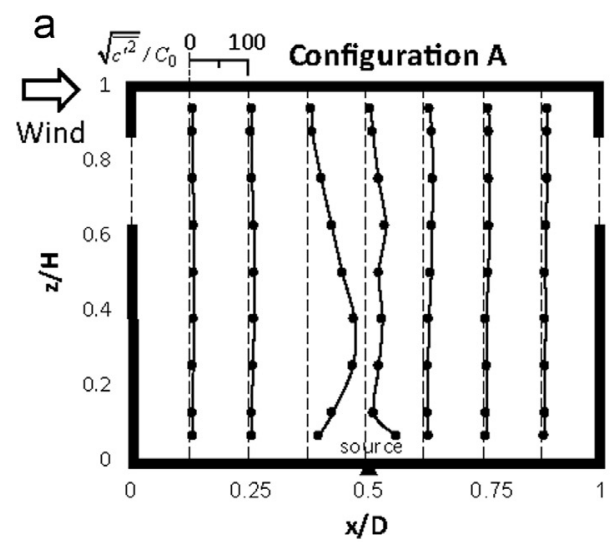

b

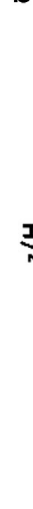

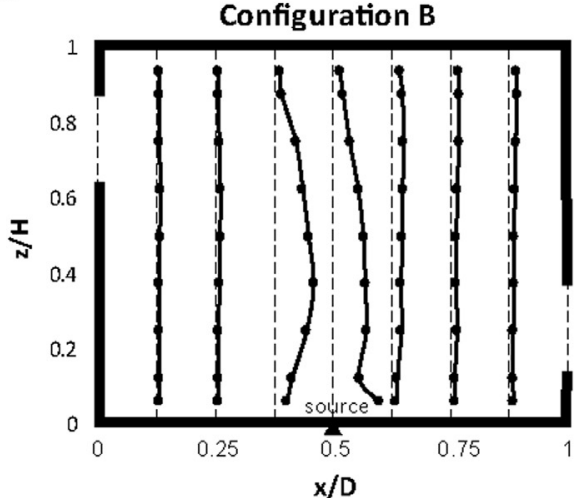

$\mathrm{x} / \mathrm{D}$

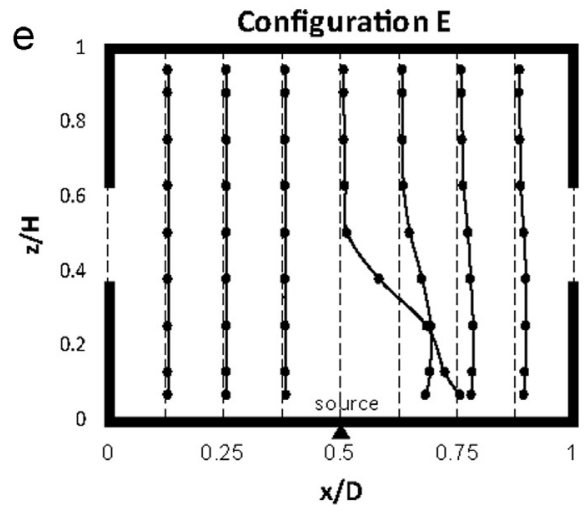

C

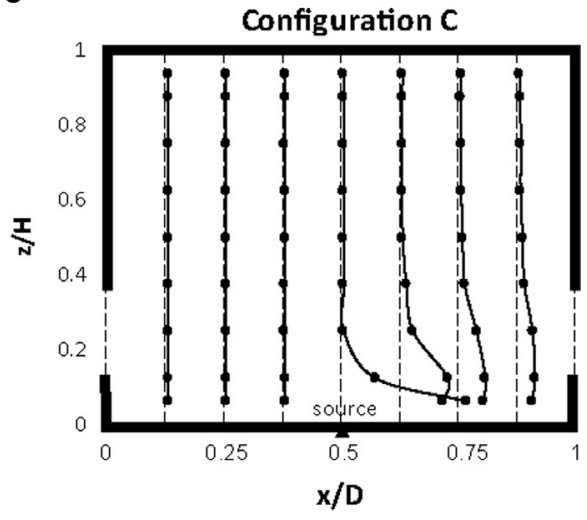

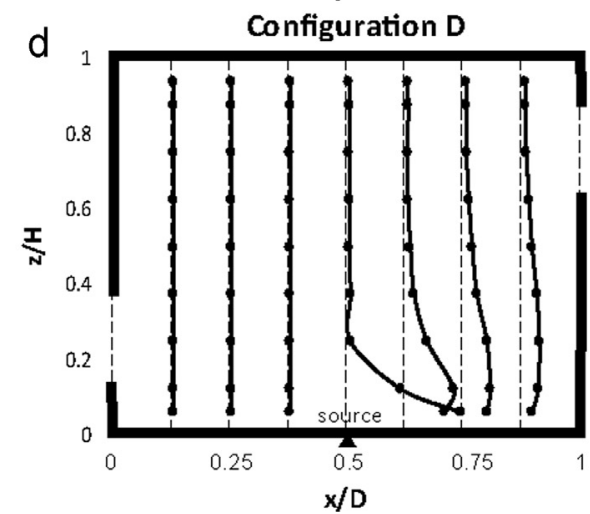

Fig. 16. Vertical profiles of RMS value of concentrations $\sqrt{c^{\prime 2}} / C_{0}$ in vertical centerplane for configurations $A, B, C, D$ and E.

Table 1

Comparison of air flow rates for all configurations.

\begin{tabular}{ll}
\hline Configurations & Air flow rate $Q / U_{H} A_{\text {inlet }}$ \\
\hline A & 0.37 \\
B & 0.27 \\
C & 0.23 \\
D & 0.22 \\
E & 0.25 \\
\hline
\end{tabular}

determined by other governing geometric and flow parameters. While it is of course evident that a different pollutant source (e.g. uniform versus point source) yields a different ventilation behavior and different values for some of performance parameters, it should be noted that many ventilation studies only consider the air change rate or (mean) velocities, and disregard the actual distribution of pollutants in the indoor volume. Care should therefore be applied when evaluating ventilation performance based on only flow rates or velocities.

\section{Discussion}

To the best of our knowledge, the present paper is the first to provide detailed experimental data and a detailed analysis of the flow and dispersion process for a set of cross-ventilated generic building configurations with different opening positions. Nevertheless, it should be mentioned that this study has the following limitations, which provide directions for future research:

- The study was only performed for generic isolated, single-zone buildings with fixed building dimensions and fixed opening areas, with only one opening in the windward and one opening in the leeward facade.
- The study considered one type of approach-flow atmospheric boundary layer.

- The study only considered wind direction perpendicular to the windward and leeward facade.

- The study only considered either a uniformly distributed pollutant concentration or a point source at the floor and a given low exhaust rate.

- Measurements of velocity and concentration were only performed in the vertical centerplane. While the openings are long and horizontal and the main flow, lateral flow and dispersion will be present.

- Only velocity and concentration were measured, as opposed to pressure.

In spite of these limitations, the authors believe that this paper provides new and valuable insights on flow and dispersion in crossventilated buildings that can also be used for validation of CFD simulations and the establishment of CFD best practice guidelines to supplement existing guidelines (e.g. Casey and Wintergerste, 2000; Franke et al., 2007; Tominaga et al., 2008b; Blocken, 2015).

\section{Summary and conclusions}

This paper presents detailed experimental data and the subsequent analysis of flow and dispersion by cross-ventilation in five generic isolated single-zone buildings. The buildings only differ from each other by the position of the ventilation openings. The study was incited by the lack of experimental - but also numerical - studies of cross-ventilation with indoor dispersion for generic building configurations. The importance of such experiments is twofold. First, they provide insights in the flow and dispersion process that might be very difficult to obtain from complex case studies in which a large number of parameters are acting simultaneously and jointly influencing the 
dispersion, e.g. building geometrical details, surrounding buildings and topography, meteorological conditions (temperature, relative humidity, ...) and people, animals or plants. Second, they provide valuable data for dedicated CFD validation studies, which in turn can be used to establish CFD best practice guidelines for this type of flow and dispersion problems. This study has provided the following main observations and conclusions:

- The flow visualization shows a jet with clear flapping behavior and Kelvin-Helmholtz instability. These characteristics are strongly influenced by the position of the inlet opening, while the position of the outlet opening is rather limited. The images suggest that for a building with a uniformly distributed pollutant concentration, the highest pollutant removal rate is found for configuration $\mathrm{E}$. The reason is that for this configuration, the flapping of the jet and the Kelvin-Helmholtz instability are most pronounced, as they are not to some extent suppressed by the ceiling (as for configurations $A$ and B) or by the floor (as for configurations D and E).

- The streamlines and the profiles of streamwise velocity illustrate the presence and strength of the incoming ventilation jet, and its effect on the indoor recirculation regions driven by this jet. The nature of these recirculation regions (vortex center, size, sense of rotation) is mainly governed by the position of the inlet opening, while the position of the outlet opening is rather limited.

- The profiles of turbulent kinetic energy show large values where the velocity gradient of the horizontal component $\partial \bar{u} / \partial z$ is large, i.e. near the inlet opening, and also where the velocity gradients of the vertical component $\partial \bar{w} / \partial x$ and $\partial \bar{w} / \partial z$ are large, i.e. in the region of strong curvature in the locally separating and recirculating flow. Examples are the outlet regions in configuration B and D.

- The concentration fields are generated by the combination of the location of the point source and the indoor flow pattern. As the latter is mainly governed by the position of the inlet opening, also the concentration fields are mainly determined by this parameter. As a result, concentration fields in configurations A and B are very similar, and to a lesser extent also those in configurations $C$ and D.

- The profiles of concentration fluctuations are large where the spatial gradient of the mean concentration is large. The distributions of $k$ and $\bar{c}^{2}$ are completely different, which suggests that the turbulent fluctuations of velocity and concentration are generated by different mechanisms.

- The airflow rates for the different configurations vary within a range of $40 \%$, even though the opening areas were identical for each configuration and the internal resistance of the building zone is very low.

- In this paper, different ventilation performance parameters were considered: of the building were considered, several of which lead to a different ranking of the configurations in terms of ventilation performance. While it is of course evident that a different pollutant source (e.g. uniform versus point source) yields a different ventilation behavior and different values for some of performance parameters, it should be noted that many ventilation studies only consider the air change rate or (mean) velocities, and disregard the actual distribution of pollutants in the indoor volume. Care should therefore be applied when evaluating ventilation performance based on only flow rates or velocities.

\section{Acknowledgments}

The framework of this paper was developed during the period that the first author visited Department of the Built Environment, Eindhoven University of Technology, the Netherlands in September 2013. The authors would like to express their gratitude to the Obayashi Foundation for supporting this visit. This work was also financially supported by
LIXIL JS Foundation (No. 14-38). The authors also thank Mr. Ryo Saito, an undergraduate student at the Niigata Institute of Technology, for his invaluable assistance with the experiments, and dr. Ivo Kalkman, senior researcher at Eindhoven University of Technology, for his able and kind assistance in processing some of the measurement data.

\section{References}

Ahmad, K., Khare, M., Chaudhry, K.K., 2005. Wind tunnel simulation studies on dispersion at urban street canyons and intersections - a review. J. Wind Eng. Ind. Aerodyn. 93 (9), 697-717.

Ai, Z.T., Mak, C.M., Niu, J.L., 2013. Numerical investigation of wind-induced airflow and inter-unit dispersion characteristics in multi-story residential buildings. Indoor Air 23, 417-429.

Ai, Z.T., Mak, C.M., 2014. A study of inter-unit dispersion around multi-story buildings with single-sided ventilation under different wind directions. Atmos. Environ. 88, 1-13.

Ai, Z.T., Mak, C.M., 2015a. Large eddy simulation of wind-induced inter-unit dispersion around multi-story buildings. Indoor Air 26 (2), 259-273.

Ai, Z.T., Mak, C.M., 2015b. From street canyon microclimate to indoor environmental quality in naturally ventilated urban buildings: issues and possibilities for improvement. Build. Environ. 94 (2), 489-503.

Akabayashi, S., Mochida, A., Tominaga, Y., Yoshida, M., Sakaguchi, J., 1996. Performance of new wind tunnel of Niigata Institute of Technology. JWE 68, 95-106, in Japanese.

Awbi, H.B., 2003. Ventilation of Buildings. Spon Press, London, New York.

Bartzanas, T., Boulard, T., Kittas, C., 2004. Effect of vent arrangement on windward ventilation of a tunnel greenhouse. Biosyst. Eng. 88 (4), 479-490.

Bartzanas, T., Kittasa, C., SapounascAA, Nikita-Martzopoulouc, C., 2007. Analysis of airflow through experimental rural buildings: Sensitivity to turbulence models. Biosyst. Eng. 97, 229-239.

Blocken, B., Tominaga, Y., Stathopoulos, T., 2013. CFD simulation of micro-scale pollutant dispersion in the built environment. Build. Environ. 64, 225-230.

Blocken, B., 2014. 50 years of computational wind engineering: past, present and future. J. Wind Eng. Ind. Aerodyn. 129, 69-102.

Blocken, B., 2015. Computational fluid dynamics for urban physics: importance, scales, possibilities, limitations and ten tips and tricks towards accurate and reliable simulations. Build. Environ. 91, 219-245.

Bu, Z., Kato, S., Takahashi, T., 2010. Wind tunnel experiments on wind-induced natural ventilation rate in residential basements with areaway space. Build. Environ. 45, 2263-2272.

Carrilho da Graça, G., Chen, Q., Glicksman, L.R., Norford, L.K., 2002. Simulation of wind-driven ventilative cooling systems for an apartment building in Beijing and Shanghai. Energy Build. 34, 1-11.

Casey, M., Wintergerste, T., 2000. ERCOFTAC special interest group on quality and trust in industrial CFD: best practices guidelines. Eur. Res. Commun. Flow, Turbule. Combust

Castro, I.P., Robins, A.G., 1977. The flow around a surface-mounted cube in uniform and turbulent streams. J. Fluid. Mech. 79 (2), 307-335.

Chen, Q, 2009. Ventilation performance prediction for buildings: a method overview and recent applications. Build. Environ. 44, 848-858.

Chen, F., Yu, S.C.M., Lai, A.C.K., 2006. Modeling particle distribution and deposition in indoor environments with a new drift-flux model. Atmos. Environ. 40 357-367.

Costola, D., Blocken, B., Hensen, J.L.M., 2009. Overview of pressure coefficient data in building energy simulation and airflow network programs. Build. Environ. 44, 2027-2036.

Cui, D.J., Mak, C.M., Kwok, K.C.S., Ai, Z.T., 2016. CFD simulation of the effect of an upstream building on the inter-unit dispersion in a multi-story building in two wind directions. J. Wind Eng. Ind. Aerodyn. 150, 31-41.

Di Sabatino, S., Buccolieri, R., Salizzoni, P., 2013. Recent advancements in numerical modelling of flow and dispersion in urban areas: a short review. Int. J. Environ. Pollut. 52 (3-4), 172-191.

Etheridge, D.W., Sandberg, M., 1984. A simple parametric study of ventilation. Build. Environ. 19, 163-173.

Etheridge, D.W., Sandberg, M., 1996. Building Ventilation: Theory and Measurement. John Wiley \& Sons, Chichester, New York.

Etheridge, D.W., 2002. Nondimensional methods for natural ventilation design. Build. Environ. 37, 1057-1072.

Etheridge, D.W., 2011. Natural Ventilation of Buildings: Theory, Measurement and Design. John Wiley \& Sons.

Evola, G., Popov, V., 2006. Computational analysis of wind driven natural ventilation in buildings. Energy Build. 38, 491-501.

Finnegan, M.J., Pickering, C.A., Burge, P.S., 1984. The sick building syndrome: prevalence studies. Br. Med. J. (Clin. Res. Ed.) 289, 1573-1575.

Franke, J., Hellsten, A., Schlünzen, H., Carissimo, B., 2007. Best Practice Guideline for the CFD Simulation of Flows in the Urban Environment.

Gao, N.P., Niu, J.L., 2007. Modeling particle dispersion and deposition in indoor environments. Atmos. Environ. 41 (18), 3862-3876.

Gao, N.P., Niu, J.L., Perino, M., Heiselberg, P., 2008. The airborne transmission of infection between flats in high-rise residential buildings: tracer gas simulation. Build. Environ. 43 (11), 1805-1817. 
Haghighat, F., Rao, J., Fazio, P., 1991. The influence of turbulent wind on air change rates-a modelling approach. Build. Environ. 26, 95-109.

Heiselberg, P., Li, Y., Andersen, A., Bjerre, M., Chen, Z., 2004. Experimental and CFD evidence of multiple solutions in a naturally ventilated building. Indoor Air 14, 43-54.

Heiselberg, P., Perino, M., 2010. Short-term airing by natural ventilation-implication on IAQ and thermal comfort. Indoor Air 20, 126-140.

Hensen, J.L.M., 2004. Integrated building airflow simulation. In: Malkawi, A., Augenbroe, G. (Eds.), Advanced Building Simulation. Spon Press, New York, pp. 87-118.

Hensen, J.L.M., Lamberts, R., 2011. Building Performance Simulation for Design and Operation. Routledge, London.

Hirano, T., Kato, S., Murakami, S., Ikaga, T., Shiraishi, Y., 2006. A study on a porous residential building model in hot and humid regions: Part 1 - the natural ventilation performance and the cooling load reduction effect of the building model. Build. Environ. 41, 21-32.

Holmberg, S., Li, Y., 1998. Modelling of the indoor environment-particle dispersion and deposition. Indoor Air 8, 113-122.

Jiang, Y., Alexander, D., Jenkins, H., Arthur, R., Chen, Q., 2003. Natural ventilation in buildings: measurement in a wind tunnel and numerical simulation with largeeddy simulation. J. Wind Eng. Ind. Aerodyn. 91, 331-353.

Ji, L., Tan, H., Kato, S., Bu, Z., Takahashi, T., 2011. Wind tunnel investigation on influence of fluctuating wind direction on cross natural ventilation. Build. Environ. 46, 2490-2499.

Karava, P., Stathopoulos, T., Athienitis, A.K., 2004. Wind driven flow through openings - a review of discharge coefficients. Int. J. Vent. 3, 255-266.

Karava, P., Stathopoulos, T., Athienitis, A.K., 2007. Wind-induced natural ventilation analysis. Sol. Energy 81, 20-30.

Karava, P., 2008. Airflow Prediction in Buildings for Natural Ventilation Design: Wind Tunnel Measurements and Simulation. Department of Building, Civil and Environmental Engineering, Concordia University, Montreal Quebec.

Karava, P., Stathopoulos, T., Athienitis, A.K., 2011. Airflow assessment in crossventilated buildings with operable façade elements. Build. Environ. 46, 266-279.

Karava, P., Stathopoulos, T., 2012. Wind-induced internal pressures in buildings with large façade openings. J. Eng. Mech. 138 (4), 358-370. http://dx.doi.org 10.1061/(ASCE)EM.1943-7889.0000296.

Kato, S., Murakami, S., Mochida, A., Akabayashi, S., Tominaga, Y., 1992. Velocitypressure field of cross ventilation with open windows analyzed by wind tunnel and numerical simulation. J. Wind Eng. Ind. Aerodyn. 44, 2575-2586.

Kato, S., Murakami, S., Takahashi, T., Gyobu, T., 1997. Chained analysis of wind tunnel test and CFD on cross ventilation of large-scale market building. J. Wind Eng. Ind. Aerodyn. 67-68, 573-587.

Kubota, T., Miura, M., Tominaga, Y., Mochida, A., 2008. Wind tunnel tests on the relationship between building density and pedestrian-level wind velocity: development of guidelines for realizing acceptable wind environment in residential neighborhoods. Build. Environ. 43 (10), 1699-1708.

Lateb, M. Meroney, R.N., Yataghene, M. Fellowah, H., Saleh, F., Boufadel, M.C., 2016. On the use of numerical modelling for near-field pollutant dispersion in urban environments - a review. Environ. Pollut. 208A, 271-283.

Li, Y., Delsante, A., Symons, J., 2000. Prediction of natural ventilation in buildings with large openings. Build. Environ. 35, 191-206.

Li, Y.G., Delsante, A., 2001. Natural ventilation induced by combined wind and thermal forces. Build. Environ. 36, 59-71.

Linden, P.F., 1999. The fluid mechanics of natural ventilation. Annu. Rev. Fluid Mech. 31, 201-238.

Li, X.X., Lui, C.H., Leung, D.Y.C., Lam, K.M., 2006. Recent progress in CFD modelling of wind field and pollutant transport in street canyons. Atmos. Environ. 40 (29), 5640-5658.

Liu, X., Zhai, Z., 2007. Inverse modeling methods for indoor airborne pollutant tracking: literature review and fundamentals. Indoor Air 6, 419-438.

Liu, X.P., Niu, J.L., Gao, N.P., Perino, M., Heiselberg, P., 2007. CFD simulation of interflat air cross-contamination - a possible transmission path of infectious diseases. In: Proceedings of the Building Simulation, Vols. 1-3, pp. 900-906.

Mao, J., Gao, N., 2015. The airborne transmission of infection between flats in highrise residential buildings: a review. Build. Environ. 94 (2), 516-531.

Meroney, R.N., 2009. CFD prediction of airflow in buildings for natural ventilation. In: Proceedings of the 11th Americas Conference on Wind Engineering. San Juan, Puerto Rico, pp. 1-11.

Meroney, R.N., 2004. Wind tunnel and numerical simulation of pollution dispersion: a hybrid approach. Paper for Invited Lecture at the Croucher Advanced Study Institute, Hong Kong University of Science and Technology 6-10 December 2004

Murakami, S., Kato, S., Akabayashi, S., Mizutani, K., Kim, Y., 1991. Wind tunnel test on velocity-pressure field of cross-ventilation with open windows. ASHRAE Trans. 97, 525-538.

Murakami, S., 1993. Comparison of various turbulence models applied to a bluff body. J. Wind Eng. Ind. Aerodyn. 46 and 47, 21-36.

Nastase, I., Meslem, A., Vlad, I., Colda, I., 2011. Lobed grilles for high mixing ventilation - an experimental analysis in a full scale model room. Build. Environ. 46 (3), 547-555.

Nazaroff, W.W., 2004. Indoor particle dynamics. Indoor Air 14, 175-183.

Niu, J., Tung, T.C.W., 2008. On-site quantification of re-entry ratio of ventilation exhausts in multi-family residential buildings and implications. Indoor Air 18, $12-26$.

Norton, T., Sun, D.W., Grant, J., Fallon, R., Dodd, V., 2007. Applications of computational fluid dynamics (CFD) in the modelling and design of ventilation systems in the agricultural industry: a review. Bioresour. Technol. 98, 2386-2414.

Norton, T., Grant, J., Fallon, R., Sun, D.-W., 2009. Assessing the ventilation effectiveness of naturally ventilated livestock buildings under wind dominated conditions using computational fluid dynamics. Biosyst. Eng. 103 (1), 78-99.

Norton, T., Grant, J., Fallon, R., Sun, D.W., 2010. Optimising the ventilation configuration of naturally ventilated livestock buildings for improved indoor environmental homogeneity. Build. Environ. 45, 983-995.

Ohba, M., Lun, I., 2010. Overview of natural cross-ventilation studies and the latest simulation design tools used in building ventilation-related research. Adv. Build. Energy Res. 4, 127-166.

Pavageau, M., Schatzmann, M., 1999. Wind tunnel measurements of concentration fluctuations in an urban street canyon. Atmos. Environ. 33, 3961-3971.

Peren, J.I., van Hooff, T., Ramponi, R., Blocken, B., Leite, B.C.C., 2015. Impact of roof geometry of an isolated leeward sawtooth roof building on cross-ventilation: straight, concave, hybrid or convex? J. Wind Eng. Ind. Aerodyn. 145, 102-114.

Ramponi, R. Blocken, B., 2012a. CFD simulation of cross-ventilation for a generic isolated building: Impact of computational parameters. Build. Environ. 53, 34-48.

Ramponi, R., Blocken, B., 2012b. CFD simulation of cross-ventilation flow for different isolated building configurations: validation with wind tunnel measurements and analysis of physical and numerical diffusion effects. J. Wind Eng. Ind Aerodyn. 104-106, 408-418.

Reichrath, S., Davies, T.W., 2002. Using CFD to model the internal climate of greenhouses: past, present and future. Agronomie 22, 3-19.

Robins, A., 2003. Wind tunnel dispersion modelling: some recent and not so recent achievements. J. Wind Eng. Ind. Aerodyn. 91 (12-15), 1777-1790.

Tablada, A., De Troyer, F., Blocken, B., Carmeliet, J., Verschure, H., 2009. On natural ventilation and thermal comfort in compact urban environments-the Old Havana case. Build. Environ. 44, 1943-1958.

Tominaga, Y., Mochida, A., Murakami, S., Sawaki, S., 2008a. Comparison of various revised $k-\varepsilon$ models and LES applied to flow around a high-rise building mode with 1:1:2 shape placed within the surface boundary layer. J. Wind Eng. Ind. Aerodyn. 96 (4), 389-411.

Tominaga, Y., Mochida, A., Yoshie, R., Kataoka, H., Nozu, T., Yoshikawa, M., et al., 2008b. AIJ guidelines for practical applications of CFD to pedestrian wind environment around buildings. J. Wind Eng. Ind. Aerodyn. 96, 1749-1761.

Tominaga, Y., Stathopoulos, T., 2011. CFD modeling of pollution dispersion in a street canyon: Comparison between LES and RANS. J. Wind Eng. Ind. Aerodyn. 99 (4), 340-348.

Tominaga, Y., Stathopoulos, T., 2013. CFD simulation of near-field pollutant dispersion in the urban environment: a review of current modelling techniques. Atmos. Environ. 79, 716-730.

Tominaga, Y., Blocken, B., 2015. Wind tunnel experiments on cross-ventilation flow of a generic building with contaminant dispersion in unsheltered and sheltered conditions. Build. Environ. 2015 (92), 452-461.

van Hooff, T., Blocken, B., 2010a. Coupled urban wind flow and indoor natura ventilation modelling on a high-resolution grid: a case study for the Amsterdam ArenA stadium. Environ. Modell. Softw. 25, 51-65.

van Hooff, T., Blocken, B., 2010b. On the effect of wind direction and urban surroundings on natural ventilation of a large semi-enclosed stadium. Comput. Fluids 39, 1146-1155.

van Hooff, T., Blocken, B., Defraeye, T., Carmeliet, J., van Heijst, G.J.F., 2012a. PIV measurements and analysis of transitional flow in a reduced-scale model: ventilation by a free plane jet with Coanda effect. Build. Environ. 56, 301-313.

van Hooff, T., Blocken, B., Defraeye, T., Carmeliet, J., van Heijst, G.J.F., 2012b. PIV measurements of a plane wall jet in a confined space at transitional slot Reynolds numbers. Exp. Fluids 53, 499-517.

van Hooff, T., Blocken, B., 2012. Full-scale measurements of indoor environmental conditions and natural ventilation in a large semi-enclosed stadium: possibilities and limitations for CFD validation. J. Wind Eng. Ind. Aerodyn. 104-106, 330-341.

van Hooff, T., Blocken, B., 2013. CFD evaluation of natural ventilation of indoor environments by the concentration decay method: $\mathrm{CO}_{2}$ gas dispersion from a semi-enclosed stadium. Build. Environ. 61, 1-17.

van Hooff, T., Blocken, B., van Heijst, G.J.F., 2013. On the suitability of steady RANS CFD for forced mixing ventilation at transitional slot Reynolds numbers. Indoor Air 23 (3), 236-249.

van Hooff, T., Blocken, B., Gousseau, P., van Heijst, G.J.F., 2014. Counter-gradient diffusion in a slot-ventilated enclosure assessed by LES and RANS. Comput. Fluids 96, 63-75.

Yoshie, R., Mochida, A., Tominaga, Y., Kataoka, H., Harimoto, K., Nozu, T., Shirasawa, T., 2007. Cooperative project for CFD prediction of pedestrian wind environment in the Architectural Institute of Japan. J. Wind Eng. Ind. Aerodyn. 95 (911), 1551-1578.

Zhang, Z., Chen, Q., 2006. Experimental measurements and numerical simulations of particle transport and distribution in ventilated rooms. Atmos. Environ. 40 (18), 3396-3408.

Zhao, B., Li, X., Zhang, Z., Huang, D., 2004. Comparison of diffusion characteristics of aerosol particles in different ventilated rooms by numerical method. ASHRAE Trans. 110, 88-95. 